\title{
QUEEN'S
UNIVERSITY
BELFAST
}

\section{In vitro release testing methods for drug-releasing vaginal rings}

Boyd, P., Variano, B., Spence, P., McCoy, C. F., Murphy, D., Dallal Bashi, Y., \& Malcolm, R. K. (2019). In vitro release testing methods for drug-releasing vaginal rings. Journal of Controlled Release.

https://doi.org/10.1016/j.jconrel.2019.10.015

Published in:

Journal of Controlled Release

Document Version:

Peer reviewed version

Queen's University Belfast - Research Portal:

Link to publication record in Queen's University Belfast Research Portal

\section{Publisher rights}

Copyright 2019 Elsevier.

This manuscript is distributed under a Creative Commons Attribution-NonCommercial-NoDerivs License

(https://creativecommons.org/licenses/by-nc-nd/4.0/), which permits distribution and reproduction for non-commercial purposes, provided the author and source are cited.

\section{General rights}

Copyright for the publications made accessible via the Queen's University Belfast Research Portal is retained by the author(s) and / or other copyright owners and it is a condition of accessing these publications that users recognise and abide by the legal requirements associated with these rights.

Take down policy

The Research Portal is Queen's institutional repository that provides access to Queen's research output. Every effort has been made to ensure that content in the Research Portal does not infringe any person's rights, or applicable UK laws. If you discover content in the Research Portal that you believe breaches copyright or violates any law, please contact openaccess@qub.ac.uk. 


\section{In vitro release testing methods for drug-releasing vaginal rings}

Peter Boyd $^{\mathrm{a}}$, Bruce Variano ${ }^{\mathrm{b}}$, Patrick Spence ${ }^{\mathrm{c}}$, Clare F. McCoy ${ }^{\mathrm{a}}$, Diarmaid J. Murphya, Yahya Bashi ${ }^{\mathrm{a}}$, R. Karl Malcolm*a

${ }^{a}$ School of Pharmacy, Queen's University Belfast, Belfast BT9 7BL, UK

${ }^{b}$ Population Council, One Dag Hammarskjold Plaza, New York, NY 10017, USA

c International Partnership for Microbicides, Silver Spring, Maryland 20910, USA

*Corresponding author. Tel: +44 (0)28 9097 2319; E-mail: k.malcolm@qub.ac.uk 


\begin{abstract}
Drug-releasing vaginal rings are torus-shaped devices, generally fabricated from thermoplastics or silicone elastomers, used to administer pharmaceutical drugs to the human vagina for periods typically ranging from three weeks to twelve months. One of the most important product performance tests for vaginal rings is the in vitro release test. Although it has been fifty years since the a vaginal ring device was first described in the scientific literature, and despite seven drug-releasing vaginal rings having been approved for market, there is no universally accepted method for testing in vitro drug release, and only one non-compendial shaking incubator method (for the estradiol-releasing ring Estring $\left.{ }^{\circledR}\right)$ is described in the US Food and Drug Administration's Dissolution Methods Database. Here, for the first time, we critically review the diverse range of test methods that have been described in the scientific literature for testing in vitro release of drugreleasing vaginal rings. Issues around in vitro-in vivo correlation and modelling of in vitro release data are also discussed.
\end{abstract}

\title{
Keywords
}

Dissolution testing; In vitro release testing; Intravaginal rings; Sustained release; Controlled release; Sink conditions; Novel dosage form; IVIVC; Release models 


\section{Introduction}

Drug-releasing vaginal rings are flexible annular-shaped devices - mostly fabricated from medical grade silicone elastomers or thermoplastic polymers - that offer sustained or controlled delivery of therapeutic agents to the vagina for clinical benefit [1-4]. Since the concept of a polymeric vaginal ring for continuous drug administration was first described in a 1968 patent application [5], seven vaginal ring products have been approved for marketing $\left(\right.$ Estring $^{\circledR}$, Nuvaring $^{\circledR}$, Femring $^{\circledR}$, Progering $^{\circledR}$, Fertiring $^{\circledR}$, Ornibel $^{\circledR}$ and Annovera ${ }^{\circledR}$; Table 1). One other ring device - a vaginal ring providing sustained release of the antiretroviral compound dapivirine for HIV prevention - is currently under review by the European Medicines Agency (EMA), and many others are in preclinical and clinical development (Table 1) [1].

In accordance with compendial requirements, two types of in vitro test are generally performed for drug-releasing vaginal rings: product quality tests and product performance tests [6]. Product quality tests are used to assess drug product quality attributes of vaginal rings, and include items such as assay value (drug content), drug substance and drug product identification, content uniformity, related substances, degradation products, microbial limits, etc. $[7,8]$. Mechanical testing is also considered an important product quality test for drug-releasing vaginal rings $[9,10]$. By comparison, performance tests for drug products invariably involve assessment of in vitro drug release. For oral immediate release dosage forms, these tests are commonly referred to as 'dissolution tests', reflecting the fact that drug release is generally achieved by disintegration and/or dissolution of the dosage form. However, for many non-oral dosage forms, including vaginal rings, the drug product itself does not generally disintegration of dissolve. Instead, the incorporated drug substance(s) is commonly released relatively 
slowly from the device via a permeation mechanism (usually involving passive diffusion of solubilised drug molecules through a polymeric material), and often over an extended period of time. Here, it is preferable to use the term 'in vitro drug release testing', or simply 'in vitro release testing', commonly abbreviated to IVRT. The aim of in vitro release testing is to characterise the drug product to ensure consistent product batch quality within a defined set of specification criteria, and to act, where possible, as a surrogate for assessment or prediction of in vivo performance $[11,12]$.

Interest in vaginal ring technology for drug delivery applications has piqued in recent years, driven primarily by a surge of innovation around the use of new ring designs and new polymeric materials for fabrication of rings. In fact, much of this innovation has stemmed directly from efforts to develop antiretroviral-releasing rings for prevention of HIV infection and multi-purpose prevention technologies the combine HIV prevention with contraception and prevention of other sexually transmitted infections $[1-3,10,13-$ 29]. In particular, great advances have been made in extending ring technology beyond conventional low molecular weight and relatively hydrophobic drugs to the formulation and release of hydrophilic drugs, biomolecular drugs and drug combinations. Fig. 1 illustrates the extended range of drug molecules for which new approaches to vaginal ring formulation are now being considered. 
1 Table 1. Descriptions of vaginal rings (both marketed products and products currently undergoing clinical testing) and details of in vitro

2 testing methods.

3

\begin{tabular}{|c|c|c|c|c|c|c|c|c|c|}
\hline $\begin{array}{l}\text { Vaginal ring } \\
\text { (Status) }^{\#}\end{array}$ & Developer & $\begin{array}{l}\text { Device type } \\
\text { I duration of } \\
\text { release }\end{array}$ & $\begin{array}{l}\text { Active agent(s) } \\
\text { (loading / release } \\
\text { rate) }\end{array}$ & Polymer & Indication & Apparatus & $\begin{array}{l}\text { Medium, volume, } \\
\text { speed }^{\dagger}\end{array}$ & $\begin{array}{l}\text { Sampling } \\
\text { timepoints }\end{array}$ & References \\
\hline $\begin{array}{l}\text { Estring } \\
\text { (A) }\end{array}$ & $\begin{array}{l}\text { Pharmacia \& } \\
\text { Upjohn }\end{array}$ & $\begin{array}{l}\text { reservoir } \\
3 \text { months }\end{array}$ & $\begin{array}{l}17 \beta \text {-estradiol } \\
(2 \mathrm{mg} / 7.5 \mu \mathrm{g} / \text { day })\end{array}$ & $\begin{array}{l}\text { silicone } \\
\text { elastomer core } \\
\text { and sheath }\end{array}$ & ERT & $\begin{array}{l}\text { linear shaking water } \\
\text { bath or shaking } \\
\text { incubator / } \\
\text { dissolution medium } \\
\text { changed periodically }\end{array}$ & $\begin{array}{l}\text { - } 0.9 \% \text { saline } \\
\text { - } 250 \mathrm{~mL} \\
\text { - } 60 \text { or } 130 \mathrm{rpm}\end{array}$ & $\begin{array}{l}\text { Medium } \\
\text { sampled and } \\
\text { replaced days } 1 \text {, } \\
9,16,17,18 \\
19,45 \text { days }\end{array}$ & {$[30,31]$} \\
\hline $\begin{array}{l}\text { Nuvaring } \\
\text { (A) }\end{array}$ & Merck & $\begin{array}{l}\text { reservoir } \\
21 \text { days }\end{array}$ & $\begin{array}{l}\text { etonogestrel } \\
(11.7 \mathrm{mg} / 120 \mu \mathrm{g} / \text { day }) \\
\text { ethinyl estradiol } \\
(2.7 \mathrm{mg} / 15 \mu \mathrm{g} / \text { day })\end{array}$ & $\begin{array}{l}28 \% \text { EVA } \\
\text { copolymer core } \\
\text { and } 9 \% \text { EVA } \\
\text { sheath }\end{array}$ & contraception & $\begin{array}{l}\text { incubator with } \\
\text { magnetic bar stirring } \\
\text { / ring suspended in } \\
\text { flask with nylon } \\
\text { string }\end{array}$ & $\begin{array}{l}\text { - water } \\
\text { - } 200 \mathrm{~mL} \\
\text { - } 750 \mathrm{rpm}\end{array}$ & NA & [32-35] \\
\hline $\begin{array}{l}\text { Femring }^{\circledR} \\
\text { (A) }\end{array}$ & $\begin{array}{l}\text { Actavis / } \\
\text { Warner } \\
\text { Chilcott }\end{array}$ & $\begin{array}{l}\text { reservoir } \\
3 \text { months }\end{array}$ & $\begin{array}{l}17 \beta \text {-estradiol-3- } \\
\text { acetate } \\
(12.4,24.8 \mathrm{mg} / 50, \\
100 \mu \mathrm{g} / \text { day })\end{array}$ & $\begin{array}{l}\text { silicone } \\
\text { elastomer core } \\
\text { and sheath }\end{array}$ & ERT & $\begin{array}{l}\text { shaking orbital } \\
\text { incubator / ring } \\
\text { suspended by } \\
\text { thread / dissolution } \\
\text { medium replaced } \\
\text { daily }\end{array}$ & $\begin{array}{l}\text { - } 0.9 \% \text { w/w saline } \\
\text { - } 0.133 \text { or } 1.0 \% \\
\text { w/v } \\
\text { benzalkonium } \\
\text { chloride } \\
\text { - } 500 \mathrm{~mL} \\
\text { - } \mathrm{rpm} \text { not specified }\end{array}$ & NA & {$[36]$} \\
\hline $\begin{array}{l}\text { Progering } \\
\text { (A) }\end{array}$ & $\begin{array}{l}\text { Population } \\
\text { Council // } \\
\text { Silesia SA / } \\
\text { Grupo } \\
\text { Grünenthal } \\
\text { Chile }\end{array}$ & $\begin{array}{l}\text { matrix } \\
3 \text { months }\end{array}$ & $\begin{array}{l}\text { progesterone } \\
(2074 \mathrm{mg} / \sim 10 \\
\mathrm{mg} / \text { day })\end{array}$ & $\begin{array}{l}\text { silicone } \\
\text { elastomer }\end{array}$ & $\begin{array}{l}\text { post-partum } \\
\text { contraception in } \\
\text { breastfeeding } \\
\text { women }\end{array}$ & $\begin{array}{l}\text { constant-flow } \\
\text { release system } \\
\text { comprising } \\
\text { peristaltic pump and } \\
\text { ring suspended in } \\
\text { flask with nylon } \\
\text { string }\end{array}$ & $\begin{array}{l}\text { - isotonic saline } \\
\text { - } 250 \mathrm{~mL} \\
\text { - } 4 \mathrm{~L} / \text { day }\end{array}$ & NA & [37-39] \\
\hline $\begin{array}{l}\text { Fertiring }^{\circledast} \\
\text { (A) }\end{array}$ & $\begin{array}{l}\text { Population } \\
\text { Council/Sile } \\
\text { sia SA/ } \\
\text { Grupo } \\
\text { Grünenthal } \\
\text { Chile }\end{array}$ & $\begin{array}{l}\text { matrix } \\
7 \text { days }\end{array}$ & $\begin{array}{l}\text { Progesterone } \\
(1000 \mathrm{mg} / \sim 10 \\
\mathrm{mg} / \text { day })\end{array}$ & $\begin{array}{l}\text { silicone } \\
\text { elastomer }\end{array}$ & $\begin{array}{l}\text { IVF / hormone } \\
\text { supplementation }\end{array}$ & same as Progering ${ }^{\circledR}$ & same as Progering $^{\circledR}$ & NA & \\
\hline $\begin{array}{l}\text { Ornibel }^{\circledR} / \\
\text { Myring }{ }^{\mathrm{TM}} \\
\text { (A) }\end{array}$ & $\begin{array}{l}\text { INSUD } \\
\text { PHARMA / } \\
\text { Exeltis }\end{array}$ & $\begin{array}{l}\text { reservoir } \\
21 \text { days }\end{array}$ & $\begin{array}{l}\text { etonogestrel } \\
(11.0 \mathrm{mg} / 120 \mu \mathrm{g} / \text { day }) \\
\text { ethinyl estradiol } \\
(3.47 \mathrm{mg} / 15 \mu \mathrm{g} / \text { day })\end{array}$ & $\begin{array}{l}\text { polyurethane } \\
\text { sheath and } 28 \% \\
\text { EVA copolymer } \\
\text { core }\end{array}$ & contraception & shaking incubator & $\begin{array}{l}\text { - sodium acetate } \\
\text { solution }(25 \mathrm{mM} \text {, } \\
\mathrm{pH} 4.2)+0.05 \% \\
\text { Solutol HS } 15\end{array}$ & NA & {$[40]$} \\
\hline
\end{tabular}




\begin{tabular}{|c|c|c|c|c|c|c|c|c|c|}
\hline & & & & & & & $\begin{array}{l}\text { - } 100 \mathrm{~mL} \\
\text {. } 60 \mathrm{rpm}\end{array}$ & & \\
\hline $\begin{array}{l}\text { Annovera }{ }^{\circledR} \\
\text { (A) }\end{array}$ & $\begin{array}{l}\text { Population } \\
\text { Council }\end{array}$ & $\begin{array}{l}\text { reservoir } \\
1 \text { year }\end{array}$ & $\begin{array}{l}\text { Nestorone }{ }^{\circledR} \\
(103 \mathrm{mg} / 150 \mu \mathrm{g} / \text { day }) \\
\text { ethinyl estradiol } \\
(17.4 \mathrm{mg} / 13 \mu \mathrm{g} / \text { day })\end{array}$ & $\begin{array}{l}\text { silicone } \\
\text { elastomer cores } \\
\text { (x2) and sheath }\end{array}$ & contraception & $\begin{array}{l}\text { linear shaking water } \\
\text { bath ( } 1 \text { inch) / ring } \\
\text { suspended in flask } \\
\text { with nylon string }\end{array}$ & $\begin{array}{l}\text { - water } \\
\text { - } 400 \mathrm{~mL} \\
\text { - } 100 \mathrm{opm} \\
\text { - 1-inch stroke } \\
\text { length }\end{array}$ & $\begin{array}{l}\text { Medium } \\
\text { sampled and } \\
\text { replaced every } \\
24 \mathrm{~h} \text { on } \\
\text { weekdays }\end{array}$ & \\
\hline $\begin{array}{l}\text { Dapivirine } \\
\text { ring (Ring- } \\
004) \\
(R)\end{array}$ & IPM & $\begin{array}{l}\text { matrix } \\
28 \text { days }\end{array}$ & $\begin{array}{l}\text { dapivirine } \\
(25 \mathrm{mg} / 2600-180 \\
\mu \mathrm{d} / \text { day in IPA+water } / \\
350-100 \mu \mathrm{g} / \text { day in } \\
\text { SVT+Tween })\end{array}$ & $\begin{array}{l}\text { silicone } \\
\text { elastomer }\end{array}$ & HIV prevention & $\begin{array}{l}\text { orbital shaking } \\
\text { incubator }(25 \mathrm{~mm}) / \\
\text { screw-cap glass } \\
\text { flasks }\end{array}$ & $\begin{array}{l}\text { - IPA+water }(1: 1 \\
\text { v/v) or SVF+0.2\% } \\
\text { Tween } 80 \\
\text { - } 100 \mathrm{~mL} \\
\text { weekdays, } 200 \\
\text { mL weekend } \\
\text { - } 60 \mathrm{rpm} \\
\text { - } 25 \mathrm{~mm} \text { orbital } \\
\text { diameter }\end{array}$ & $\begin{array}{l}\text { Medium } \\
\text { sampled and } \\
\text { replaced every } \\
24 \mathrm{~h} \text { on } \\
\text { weekdays }\end{array}$ & {$[7,8,41]$} \\
\hline $\begin{array}{l}\text { tenofovir and } \\
\text { tenofovir }+ \\
\text { levonorgestre } \\
\text { I rings }\end{array}$ & CONRAD & $\begin{array}{l}\text { Segmented } \\
\text { dual- } \\
\text { reservoir } \\
90 \text { days }\end{array}$ & $\begin{array}{l}\text { tenofovir }(1.2-1.6 \mathrm{~g} / \\
10 \mathrm{mg} / \text { day) } \\
\text { levonorgestrel }(6 \mathrm{mg} / \\
20 \mu \mathrm{g} / \text { day) }\end{array}$ & polyurethane & $\begin{array}{l}\text { HIV prevention, } \\
\text { contraception }\end{array}$ & $\begin{array}{l}\text { shaking incubator / } \\
250 \text { or } 500 \mathrm{~mL} \text { glass } \\
\text { flasks }\end{array}$ & $\begin{array}{l}\text { - } 25 \mathrm{mM} \text { sodium } \\
\text { acetate buffer, } \\
\text { pH } 4.2 \\
\text { - Volumes } \\
\text { adjusted } \\
\text { throughout the } \\
\text { experiment } \\
\text { - } 80 \mathrm{rpm}\end{array}$ & $\begin{array}{l}\text { Medium } \\
\text { replaced every } \\
24 \mathrm{~h} \text { on } \\
\text { weekdays }\end{array}$ & {$[15,42,43]$} \\
\hline $\begin{array}{l}\text { Combination } \\
\text { MZCL ring } \\
\text { (D) }{ }^{1}\end{array}$ & $\begin{array}{l}\text { Population } \\
\text { Council }\end{array}$ & $\begin{array}{l}\text { core-matrix } \\
90 \text { days }\end{array}$ & $\begin{array}{l}\text { MIV-150 (3 mg / > } 4 \\
\mu g / \text { day) } \\
\text { zinc acetate }(30 \mathrm{mg} / \\
>50 \mu \mathrm{g} / \text { day) } \\
\text { carrageenan ( } 70 \mathrm{mg} / \\
>100 \mu \mathrm{g} / \text { day) } \\
\text { levonorgestrel }(0.6 \mathrm{mg} \\
\text { / > } 2 \mu \mathrm{g} / \text { day) }\end{array}$ & $\begin{array}{l}\text { ethylene vinyl } \\
\text { acetate }(28) \\
\text { core with a } 500 \\
\text { or } 800 \mu \mathrm{m} \text { pore }\end{array}$ & $\begin{array}{l}\text { HIV prevention, } \\
\text { HSV-2 } \\
\text { prevention, HPV } \\
\text { prevention and } \\
\text { contraception }\end{array}$ & shaking incubator & $\begin{array}{l}\text { - } 25 \mathrm{mM} \text { acetate } \\
\text { buffer, pH } 4.2 \\
\text { - } 10 \mathrm{~mL} \text { daily } \\
\text { - } 100 \mathrm{rpm}\end{array}$ & $\begin{array}{l}\text { Medium } \\
\text { replaced every } \\
24 \mathrm{~h} \text { on } \\
\text { weekdays and } \\
\text { sampled } \\
\text { periodically }\end{array}$ & {$[14,27]$} \\
\hline $\begin{array}{l}\text { Multipurpose } \\
\text { pod- } \\
\text { intravaginal } \\
\text { ring }(D)^{2}\end{array}$ & $\begin{array}{l}\text { Oak Crest } \\
\text { Institute of } \\
\text { Science }\end{array}$ & $\begin{array}{l}\text { pod ring } \\
35 \text { days }\end{array}$ & $\begin{array}{l}\text { tenofovir alafenamide } \\
\text { hemifumarate ( } 45 \mathrm{mg} \text { / } \\
400 \mu \mathrm{\mu g} / \mathrm{day}) \text { acyclovir } \\
\text { ( } 4 \mathrm{mg} / 700 \mu \mathrm{\mu g} / \mathrm{day}) \\
\text { etonogestrel (11 or } 22 \\
\mathrm{mg} / 600 \mu \mathrm{g} / \mathrm{day}) \\
\text { ethinyl estradiol (11 } \\
\mathrm{mg} / 55 \mu \mathrm{g} / \mathrm{day})\end{array}$ & $\begin{array}{l}\text { silicone } \\
\text { elastomer }\end{array}$ & $\begin{array}{l}\text { HIV prevention, } \\
\text { HSV prevention } \\
\text { and } \\
\text { contraception }\end{array}$ & $\begin{array}{l}\text { orbital shaking } \\
\text { incubator }\end{array}$ & $\begin{array}{l}\text { - } 25 \mathrm{mM} \text { acetate } \\
\text { buffer, pH } 4.2+ \\
\text { NaCl to } 220 \mathrm{mOs} \\
\text { - } 100 \mathrm{~mL} \\
\text { - } 60 \mathrm{rpm}\end{array}$ & $\begin{array}{l}\text { Medium } \\
\text { replaced daily or } \\
\text { samples } \\
\text { removed and } \\
\text { replaced } \\
\text { periodically }\end{array}$ & {$[22,44-46]$} \\
\hline
\end{tabular}


5 Abbreviations (in alphabetical order): ERT - estrogen replacement therapy; EVA - ethylene vinyl acetate copolymer; HIV - human immunodeficiency virus; IPA isopropanol; IPM - International Partnership for Microbicides; IVF - in vitro fertilization; NA - data not available; opm - linear oscillations per minute; rpm - revolutions per minutes; SVF - simulated vaginal fluid.

$8 \quad \#(A)$ - approved; $(R)$ - under review; (D) - in clinical development

$9+$ All in vitro tests are performed at $37^{\circ} \mathrm{C}$.

101 Macaque-sized ring and target release rates reported.

112 Macaque and human-sized rings reported. Also, several drug combinations were investigated, including tenofovir disoproxil fumarate with emtricitabine and the 12 monoclonal antibody VRC01-N. 


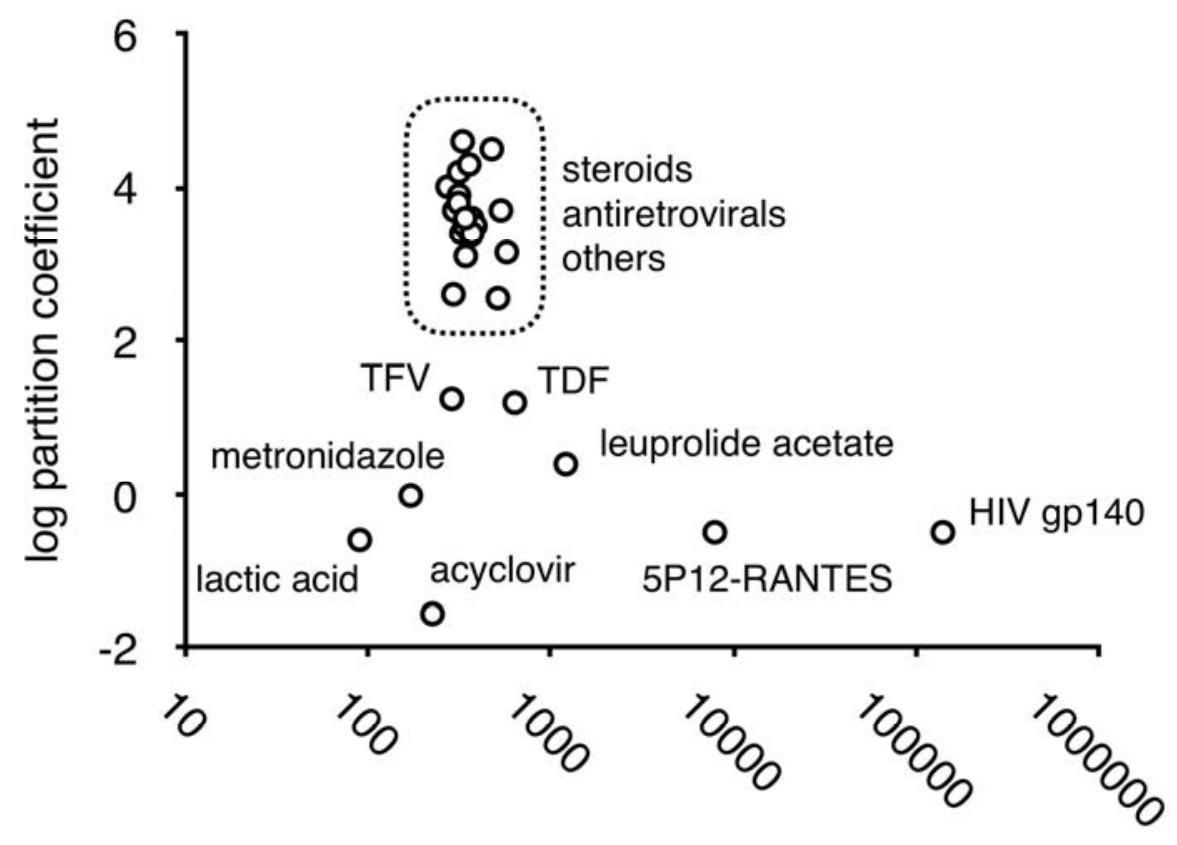

Molecular weight $(\mathrm{g} / \mathrm{mol})$

16 Fig. 1. Plot of $\log \mathrm{P}$ (experimental or calculated log partition coefficients; protein

17 molecules arbitrarily assigned a value of 1) vs. molecular weight for drug compounds

18 investigated in vaginal rings. Plot symbols inside the dashed box include estradiol,

19 ethinyl estradiol, etonogestrel, estradiol-3- acetate, dapivirine, progesterone,

20 levonorgestrel, maraviroc, MIV-150, oxybutynin, segesterone acetate (Nestorone $\left.{ }^{\circledR}\right)$,

21 norethindrone acetate, ulipristal acetate, medroxyprogesterone acetate, UC781, danazol,

22 MC1220, CMPD-167, drosperinone, nomegestol acetate, and vicriviroc. Labelled

23 molecules outside the dashed box are currently being considered for vaginal ring

24 formulations and that, due to physiochemical constraints, generally require novel

25 formulation approaches. Figure and caption used with permission (McBride et al., 26 2019a). 


\section{General principles of in vitro release testing for vaginal rings}

\subsection{Background}

Currently, there is no established compendial apparatus or method for in vitro release testing of vaginal rings. Moreover, existing apparatus and methods used for dissolution testing of more conventional dosage forms are often unsuitable for vaginal rings. For example, based on unpublished data from within our own research group, release testing of rings using USP Apparatus 2 (rotating paddle) leads to very significant loss of release medium between daily sampling timepoints due to evaporation, both for aqueous-based media and particularly for solvent/water media. Theoretically, USP Apparatus 4 (flowthrough cell) would seem a good option for in vitro release testing of vaginal rings, since the closed system minimises evaporation of medium and the rate of flow can be easily adjusted to mimic the dynamics of vaginal fluid production in vivo [47]. However, a major limitation of existing Apparatus 4 systems is the small size of the flow cells for housing the test device, such that full-sized ring devices cannot usually be accommodated. Cutting vaginal rings into smaller segments for testing in Apparatus 4 is also not recommended, since the drug release characteristics for the ring segments would be different from that of the full ring product. This is particularly true for reservoir-type rings, which comprise a drug-loaded core encapsulated by a non-medicated ratecontrolling membrane; cutting a segment from the ring would directly expose the drugloaded core to the release medium. Some researchers have sought to overcome this limitation by using ring segments having high-density polyethylene caps glued to the ends of the segments $[25,48,49]$. Even for ring devices that can be inserted into a flowthrough cell, the ring often needs to be folded and squeezed beyond what would normally be encountered in vivo, potentially impacting both the extent of ring exposure to the release medium and fluid dynamics around the device. 
53 2.2. Key criteria for in vitro release testing of vaginal rings

54 Selection of experimental apparatus, release media, and release methods for in vitro

55 release testing of vaginal rings is largely governed by the nature of both the drug and the

56 device. However, certain key criteria should be carefully considered, including: (i) the

57 method should be biorelevant, i.e. should mimic as closely as possible physiological

58 conditions in the vagina, (ii) the system should comprise well-defined components for

59 reproducibility of results, (iii) simplicity of design of experimental apparatus is

60 preferable, (iv) the test apparatus should be convenient in terms of handling, operation

61 and cleaning, (v) it should be easy to introduce the test product into the testing systems,

62 and to withdraw release medium samples for analysis, (vi) the method should allow

63 effective and controlled agitation, (vii) the method should be easily adapted for use in

64 accelerated drug release tests, and (viii) the method should be economical [50]. 
65 Table 2. Drug product factors and release test parameters that can affect the in vitro drug

66 release performance of vaginal rings.

67

\begin{tabular}{ll}
\hline Drug product factors & Release test parameters \\
\hline - ring type (e.g. matrix, reservoir, pod, insert, exposed & • type of test (shake-flask vs. flow-through) \\
core, etc.) & $\bullet$ type of agitation (orbital vs. linear shaking) \\
- overall ring dimensions & $\bullet$ composition of release medium \\
- core length (for reservoir rings) & $\bullet$ volume of release medium \\
- membrane thickness (for reservoir rings) & - sink vs non-sink conditions \\
- drug type & $\bullet$ sampling frequency and interval \\
- drug solubility in the ring polymer & $\bullet$ frequency of medium replacement \\
- drug diffusivity in the ring polymer & $\bullet$ rate of stirring \\
- initial drug loading (for matrix rings) & $\bullet$ rate and diameter of orbital shaking \\
- drug particle size distribution & $\bullet$ temperature of release medium / prewarming of medium \\
- salt form of drug & $\bullet$ position of ring in flask (suspended or lying flat) \\
- polymorphic form of drug & $\bullet$ type of flask / shape of flask (affects fluid dynamics \\
- co-formulation / drug-drug interactions & around the ring) \\
- polymer type and grade & \\
- cure temperature and time (for silicone elastomer) & \\
- molding/extrusion temperature (thermoplastics) & \\
- formulation excipients & \\
- drug photosensitivity & \\
- ring storage / storage conditions &
\end{tabular}

69 To date, a variety of non-compendial methods for in vitro release testing of vaginal rings

70 have been reported in the literature (Table 1). Factors common to most of these methods

71 include: (i) placement of the ring device in a sealed glass flask; (ii) shaking or stirring of

72 the flask; and (iii) periodic sampling and replacement of the release medium. Typically,

73 the ring device is either allowed to rest at the bottom of the flask or suspended in the

74 medium by a string (usually nylon) (Fig. 2). 


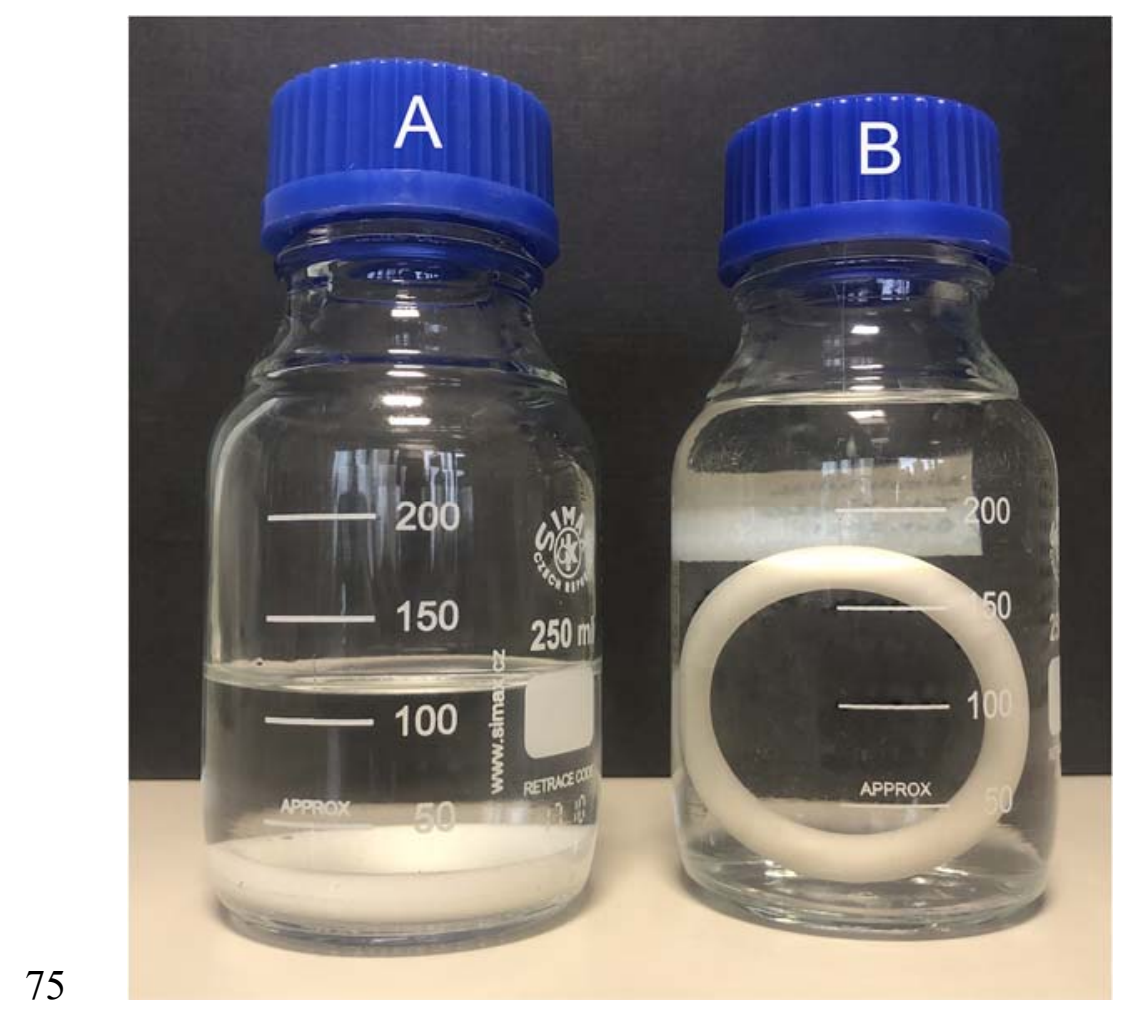

76 Fig. 2. Sealed glass flasks for in vitro release testing of vaginal rings. A - ring placed on

77 bottom of flask containing $100 \mathrm{~mL}$ of release medium. B - ring suspended by a nylon

78 thread in glass flask containing $200 \mathrm{~mL}$ release medium.

\subsection{Stirring or agitation of the release medium}

81 Reported agitation rates vary widely, from $60 \mathrm{rpm}$ when using shaking incubators (which

82 is most common) to $750 \mathrm{rpm}$ for in-flask stirring with a magnetic bar (Nuvaring ${ }^{\circledR}$ testing

83 protocol, Table 1). Just as for dissolution testing of oral doage forms, agitation rates are

84 known to significantly impact in vitro drug release from vaginal rings, although only

85 very limited data on this topic has been reported in the literature [51,52]. The thickness

86 of the aqueous diffusion layer (also known as the hydrostatic layer or the boundary

87 layer) immediately adjacent to the surface of the ring device when placed into a liquid

88 medium (in vivo or in vitro) can be readily modulated by adjusting the stirring rate,

89 which in turn influences the drug release rate. According to long-established theories of

90 drug dissolution, faster stirring rates will lead to increased drug release rates $[53,54]$. 
91 Further evaluation of the impact of stirring rates on drug release from vaginal rings could prove useful in developing methods that more closely mimic in vivo release.

\section{Dissolution media for in vitro release testing of vaginal ring}

\subsection{Types of release media}

96

A wide range of different media have been reported for in vitro release testing of marketed vaginal ring products and rings currently undergoing clinical testing (Table 1), including: water [10], saline [15], buffer solutions [14,15,55-57], aqueous surfactant solutions $[23,48,55,58]$, polyethylene glycol/water mixures [59-61], simulated vaginal fluid $[7,26,62,63]$, and organic solvent/water mixtures [7,62-68]. Although polyethylene glycol/water mixures were used in many early studies, these media see limited use today. Invariably, the release medium is judiciously selected to provide sink conditions for the $\operatorname{drug}(\mathrm{s})$ under investigation, and therefore factors such as solubility of the drug, the volume of medium used, the rate of release of $\operatorname{drug}(\mathrm{s})$ from the device, and the sampling interval are critical in guiding selection.

\subsection{Types of drugs released from vaginal rings}

All of the marketed vaginal rings and many of the rings currently undergoing development contain relatively potent ( $\mu \mathrm{g}-$ low mg daily dosing) and hydrophobic (log $\mathrm{P}$ typically $>3$ ) drug molecules (Table 1; Figure 1). Hydrophobic drugs are particularly well-suited to incorporation into and release from the hydrophobic and nonbiodegradable polymers commonly used to fabricate vaginal rings (i.e. silicone elastomer, ethylene vinyl acetate copolymer, thermoplastic polyurethanes), since it is necessary for the drug to have some degree of solubility within the polymer in order to permit molecular permeation and release. Consequently, in vitro release testing of rings 
116 often requires (i) use of relatively large volumes of aqueous release media, (ii) addition

117 of surfactants to water/buffer mixtures, or (iii) use of water-miscible organic solvents in

118 order to maintain sink conditions between sampling timepoints (Table 1).

\subsection{Sink conditions}

121 The principle of sink conditions is often poorly understood outside of those with 122 specialist knowledge of pharmaceutics and drug delivery, and yet it is one of the most 123 important considerations when developing in vitro dissolution/release methods. Here, in

124 the context of in vitro release testing of vaginal rings, we define sink conditions as

125 selection and maintenance of a release medium with sufficient solvating power such that

126 the concentration of the drug in the release medium (following drug release from the 127 ring) does not exceed $10 \%$ of its saturation concentration during the release experiment.

128 For example, dapivirine is soluble to the extent of $\sim 1200 \mu \mathrm{g} / \mathrm{mL}$ in $1: 1$ isopropanol/water

129 mixture at $37^{\circ} \mathrm{C}$. Day 1 in vitro release of dapivirine from a $25 \mathrm{mg}$ dapivirine matrix-type

130 vaginal ring into $200 \mathrm{~mL}$ is $\sim 2500 \mu \mathrm{g}$, which corresponds to $\sim 1 \%$ of saturation

131 concentration [7], significantly below the $10 \%$ sink condition threshold.

133 Sink conditions are commonly assumed for vaginal rings in vivo, even for highly water-

134 insoluble drugs and despite the very low volumes $(<2 \mathrm{~mL})$ of vaginal fluid normally

135 present [47]. From a theoretical perspective, sink conditions are more likely to be 136 operating in vivo for rings offering relatively low microgram per day release rates, such

137 as the reservoir rings Estring ${ }^{\circledR}$, Nuvaring ${ }^{\circledR}$ and Ornibel ${ }^{\circledR}$. By comparison, the marketed 138 progesterone rings Fertiring ${ }^{\circledR}$ and Progering ${ }^{\circledR}$ (Table 1), which provide release of approx. $13910 \mathrm{mg} /$ day, may saturate the vaginal fluid. Surprisingly, for many vaginal ring products, 140 it is not known (or at least it has not been reported) to what extent initial drug loading 
141 within the ring impacts systemic pharmacokinetics. For highly water-insoluble drugs

142 delivered from rings, it is entirely possible that drug saturation is maintained in vaginal

143 fluid, such that drug solubility - rather than the device itself - is rate-controlling.

144 However, the relatively large sink offered by the vaginal mucosal tissue will likely

145 compensate for poor vaginal fluid solubility of poorly water-soluble drugs. In fact, it is

146 entirely possible that drug at the ring surface could permeate directly from the ring into

147 the surrounding mucosal tissue via a ring-to-tissue partitioning process. By comparison,

148 release of relatively water-soluble molecules (having relatively low log P values) from

149 vaginal rings may quickly saturate the limited volume of vaginal fluid available, and yet

150 be effectively trapped there due to an unfavourable partition/distribution coefficient with

151 the mucosal tissue. In this scenario, sink conditions may not apply, and release could

152 theoretically be solubility controlled. Unfortunately, more fundamental studies to

153 address such issues relating to vaginal ring performance in vivo are lacking, highlighting

154 the need for further careful research.

\section{3.4. Biorelveant release media}

157 Although it is strongly encouraged, drug regulatory authorities do not strictly require the 158 selected release medium to reflect in vivo physiological conditions. Non-physiologically 159 relevant in vitro release test methods can be approved if they are demonstrated to be 160 sufficiently robust and discriminatory, i.e. capable of reliably detecting changes in the 161 dosage form that could potentially lead to changes of the drug product performance in 162 vivo.

164 Driven by efforts to provide better in vitro-in vivo correlations (IVIVCs; see later 165 section) and physiological relevance for vaginally-administered products, there has been 
166 a move in recent years towards use of release media that more closely mimic the

167 chemical composition, $\mathrm{pH}$ and volume of vaginal fluid [47,69]. Although its composition

168 is affected by contributions from cervical mucus $(\mathrm{pH} \sim 8.0)$ [70], semen $(\mathrm{pH} \sim 7.5)$ [71]

169 and menstrual material, normal vaginal fluid in pre-menopausal and post-menopausal

170 women is generally within the $\mathrm{pH}$ range $4-5$ and $>5$, respectively [47]. Daily production

171 of vaginal fluid is estimated at around $6 \mathrm{~g} /$ day, with approximately $0.5-0.75 \mathrm{~g}$ present in

172 the vagina at any time [47]. Taking the lower value within this range, the $10 \%$ solubility

173 value commonly defined for sink conditions translates to approximately $50 \mathrm{mg}$ drug in

$1740.5 \mathrm{~mL}$ of vaginal fluid. Fortunately, such large drug doses are not possible (nor

175 clinically warranted) with marketed low-dose steroid-releasing vaginal ring products.

176 However, vaginal drug doses close to or in excess of $50 \mathrm{mg}$ are not unusual for other

177 vaginally-administered products. For example, vaginal application of metronidazole gel

178 for treatment of bacterial vaginosis requires relatively high daily dosing in the range

$179 \quad 37.5-70 \mathrm{mg}$ (one or two doses daily). This level of dosing could also potentially be

180 achieved with a ring device (assuming sufficiently high release characteristics), and for

181 which sink conditions may not hold.

183 Aqueous-based media adjusted to $\mathrm{pH} 4-5$, and most notably simulated vaginal fluid

184 (SVF), are now commonly used in the in vitro dissolution/release testing of vaginal

185 dosage forms, including vaginal rings $[7,28,46,47,62,66,69,72-90]$. SVF is prepared

186 either following the published recipe [47], or additionally containing small quantities of

187 surfactants to enhance its otherwise limited solvating power (Table 1) [7,69]. SVF was

188 primarily developed to simulate the chemical composition of vaginal fluid, with a

189 particular emphasis on modelling $\mathrm{pH}$ and osmolarity; it is not intended to mimic the

190 viscosity of vaginal fluid [47]. Several surfactants have been reported for addition to 
191 SVF media, including Tween 80 (also known as Polysorbate 80), Solutol HS15 (also

192 known as Kolliphor HS15) and benzalkonium chloride (Table 1) [7,36,48,69,91-94].

\subsection{Solvent/water release media}

195 For ring devices containing very poorly water-soluble drug molecules, in vitro release

196 testing under sink conditions has been widely reported using solvent/water mixtures. In

197 fact, much of the early research into steroid-releasing vaginal rings made use of highly

198 concentrated aqueous solutions of polyethylene glycol [59-61]. More recently, for

199 vaginal rings releasing highly water-insoluble antiretroviral drugs, alcohol/water

200 mixtures have become common (Boyd et al., 2016; Fetherston et al., 2013b, 2013a;

201 Malcolm et al., 2012b, 2005; McCoy et al., 2017; Murphy et al., 2016). For example,

202 vaginal rings containing the antiretroviral drug dapivirine (water solubility $<<1 \mu \mathrm{g} / \mathrm{mL}$ )

$203[67,96]$ are routinely tested using $100 \mathrm{~mL}$ of a $1: 1 \mathrm{v} / \mathrm{v}$ mixture of isopropanol/water

204 (Table 1). In fact, similar solvent-based mixtures are used for USP compendial

205 dissolution testing of oral tablets containing the anti-malarial drug atovaquone (water

206 solubility $<0.2 \mu \mathrm{g} / \mathrm{mL}$ ) and a $5 \%$ methanol solution is used to test an injectable

207 suspension of triptorelin pamoate [31]. In general, the solvent-water ratio can be readily

208 adjusted to achieve the desired solvating power [97], and potentially to match in vivo 209 release rates.

\section{4. In vitro release test methods for vaginal rings}

212 Here, we describe in more detail the various in vitro test methods for marketed vaginal

213 rings and rings that are currently in late-stage development. For other drug-releasing

214 vaginal ring devices, the interested reader is directed to the scientific literature,

215 particularly journal articles and information provided in patents (both applications and 
216 granted). Invariably, these rings are also tested for in vitro release using similar test

217 methods to those described here. The following review articles will provide a useful

218 entry into the journal literature [1,98-100].

\subsection{Nuvaring ${ }^{\circledR}$}

221 Despite the lack of published information on the in vitro release testing method used for 222 the contraceptive vaginal ring product Nuvaring ${ }^{\circledR}$, much can be gleaned from the patent 223 literature and a supporting $\mathrm{PhD}$ thesis [33-35,101,102]. According to these sources, 224 individual Nuvaring ${ }^{\circledR}$ devices are immersed in $200 \mathrm{~mL}$ water at $37^{\circ} \mathrm{C}$ under continuous 225 stirring at $750 \mathrm{rpm}$. In order to maintain sink conditions, water is refreshed daily by an 226 auto-sampler. Based on the relatively high stirring speed reported, and the reference to 227 'stirring' in the source documents, it is assumed that a magnetic stirring bar method is 228 being used, which also explains the need to suspend the ring in the release medium using 229 a nylon string. Experimental water solubility for etonogestrel is not available. However, 230 ethinyl estradiol, has a reported $\mathrm{pH}$-dependent water solubility of between 9.1 and 10.8 $231 \mathrm{mg} / \mathrm{L}$ at $25^{\circ} \mathrm{C}(>1.8 \mathrm{mg} / 200 \mathrm{~mL})$ [103]. With a mean ethinyl estradiol release rate of 15 $232 \mu \mathrm{g} / \mathrm{day}$, the $200 \mathrm{~mL}$ release volume easily provides sink conditions over the 1-day 233 sampling interval.

235 Externbrink et al. have reported the use of a USP Apparatus 7 (reciprocating holder, 40 $236 \mathrm{dips} / \mathrm{min}$ ) to assess real-time and temperature-accelerated etonogestrel release (but not 237 ethinyl estradiol) from Nuvaring ${ }^{\circledR}$ [104]. Ring segments of length $1-1.5 \mathrm{~cm}$, having their 238 ends sealed with an acrylate glue to prevent release from the segments ends, were placed 239 into 50-mesh basket holders within individual dissolution cells containing $10 \mathrm{~mL}$ of 240 either simulated vaginal fluid with $0.1 \%$ sodium azide or water. Release experiments 
241 were conducted at $37,44,50$, and $55^{\circ} \mathrm{C}$ with automated sampling and replacement of

242 media performed every $12 \mathrm{~h}$. Etonogestrel daily release $v s$. time profiles measured at 37

$243{ }^{\circ} \mathrm{C}$ for ring segments standardised to release per ring showed slightly decreased release

244 for the USP 7 apparatus compared with the FDA-approved standard test method

$245[33,35,101,102]$. Also, etonogestrel release increased with temperature, with zero-order

246 release constants consistent with the Arrhenius equation. The closed system USP 7

247 apparatus was also useful in minimising media loss by evaporation at higher

248 temperatures, an issue that is known to impact release when using USP Apparatus 2

249 (rotating paddle) for testing of vaginal rings [Karl Malcolm; unpublished data].

$251 \quad$ 4.2. Estring ${ }^{\circledR}$

252 There are two reports of an in vitro release test method for Estring ${ }^{\circledR}$, a silicone elastomer

253 reservoir-type ring offering 90-day controlled release of $17 \beta$-estradiol for estrogen

254 replacement therapy (Table 1). The first, a 1994 journal article by Schmidt et al.,

255 describes placement of each ring in a $500 \mathrm{~mL}$ conical flask containing $250 \mathrm{~mL}$ of $0.9 \%$

256 saline, the flasks placed in linear shaking water bath at $37^{\circ} \mathrm{C}$ operating at 60 strokes $/ \mathrm{min}$

257 (Table 1) [30]. Based on literature values for estradiol water solubility of $(1.5-3.6 \mathrm{mg} / \mathrm{L}$

258 at various temperatures and $\mathrm{pH}$; i.e. $>375 \mu \mathrm{g} / 250 \mathrm{~mL}$ ) and the relatively low $17 \beta-$

259 estradiol release rate from the ring $(7.5 \mu \mathrm{g} /$ day $)$, the $250 \mathrm{~mL}$ volume of saline might

260 easily maintain sink conditions over cumulative release periods of up to 5 days [103]. A

261 modified incubator method for in vitro release testing of Estring ${ }^{\circledR}$ is also reported in the

262 FDA's Dissolution Methods Database, for which a shaking speed of $130 \mathrm{rpm}$ is used

263 [31].

264

265 4.3. Femring ${ }^{\circledR}$ 
266 No method describing the in vitro release testing of Femring ${ }^{\circledR}$ is publicly available.

267 However, as part of preclinical development of Femring ${ }^{\circledR}$, Woolfson et al. reported 90-

268 day in vitro release testing of core-type silicone elastomer vaginal rings containing $17 \beta-$

269 estradiol or one of its esters (Woolfson et al., 1999). The method involving suspending

270 each ring by a thread in an individual closed flask containing $500 \mathrm{~mL}$ of the dissolution

271 medium (either $0.9 \% \mathrm{w} / \mathrm{v}$ saline, $0.133 \% \mathrm{w} / \mathrm{v}$ or $1.0 \% \mathrm{w} / \mathrm{v}$ aqueous benzalkonium

272 chloride, BKC) maintained at a constant temperature of $37^{\circ} \mathrm{C}$ in a shaking orbital

273 incubator, with the dissolution medium renewed every 24 h. Based on solubility

274 measurements for each drug, it was determined that only the $1.0 \% \mathrm{w} / \mathrm{v}$ BKC solution

275 provided sink conditions.

\subsection{Annovera ${ }^{\circledR}$}

278 A reservoir-type, silicone elastomer, contraceptive vaginal ring offering controlled

279 release of Nestorone ${ }^{\circledR}$ (segesterone acetate) and ethinyl estradiol for one year has been

280 developed by the Population Council and recently been approved by the FDA (Table 1).

281 As with other marketed vaginal rings, a relatively large volume (400 $\mathrm{mL})$ of water is 282 used for in vitro release testing, with daily replacement of the medium to maintain sink 283 conditions. In this instance, a linear shaking water bath set to operate at 100 oscillations 284 (strokes) per minute is used to house the ring flasks during the test.

\subsection{Dapivirine ring}

287 A matrix-type silicone elastomer vaginal ring releasing dapivirine, an experimental non288 nucleoside reverse transcriptase inhibitor, has been in development since 2002 and has 289 recently completed Phase III clinical testing as a female-controlled method for 290 prevention of HIV-1 infection [68,105-107]. Numerous journal articles have reported in 
vitro release testing of vaginal rings containing either dapivirine alone or dapivirine in combination with another drug, most using a shaking incubator or shaking water-bath

293 method $[7,16,23,62,64,66,68,95,107]$. Since dapivirine has very poor solubility in

294 aqueous media $(<<1 \mu \mathrm{g} / \mathrm{mL})[67,96]$, much of the reported in vitro release data for the

295 vaginal ring describes use of a 1:1 isopropanol/water mixture in which dapivirine has 296 greatly enhanced solubility [7,64,68,97,107]. In general, compendia (USP, Ph. Eur., et

297 al.) strongly discourage the use of organic solvents for dissolution methods, allowing

298 such use only when no appropriate alternatives can be identified. However, other

299 products containing very poorly water-soluble drugs (e.g. atovaquone tablets) are tested

300 using a medium containing 40\% isopropanol [31]. For the dapivirine ring, the 1:1

301 isopropanol/water medium was found to be most suitable, although recent publications

302 have explored the use of aqueous solutions containing surfactants [7], concluding that

303 the aqueous-based medium is complementary, but not superior, to the isopropanol/water 304 medium.

\section{Apparatus for in vitro release testing of vaginal rings}

\subsection{Shaking incubator apparatus}

308 Most methods described in the literature for in vitro release testing of vaginal rings make

309 use of a temperature-controlled shaking incubator (Table 1). Examples of different types

310 of shaking incubators are presented in Fig. 3. There are three important operational

311 variables for these incubators that are known to affect drug release characteristics: (i) the

312 type of shaking, e.g. linear vs. orbital; (ii) the speed of shaking (e.g. oscillations or

313 revolutions per min); and (iii) the distance through which shaking occurs, referred to as

314 the stroke length for linear shaking incubators and orbital diameter for orbital shaking

315 incubators. Most shaking incubators will allow adjustment of the shaking speed. With 
316 some incubators, the shaking distance can also be adjusted. Changing any of these three

317 variables will modify both the dynamics of fluid flow around the ring device and, in turn,

318 the thickness of the diffusion boundary layer (the relatively static layer of fluid

319 immediately adjacent to the ring surface) $[59,108-110]$. In general, increasing the

320 shaking speed or distance leads to increased rate of drug release, although there is very

321 limited data reported in the literature on this topic [111].

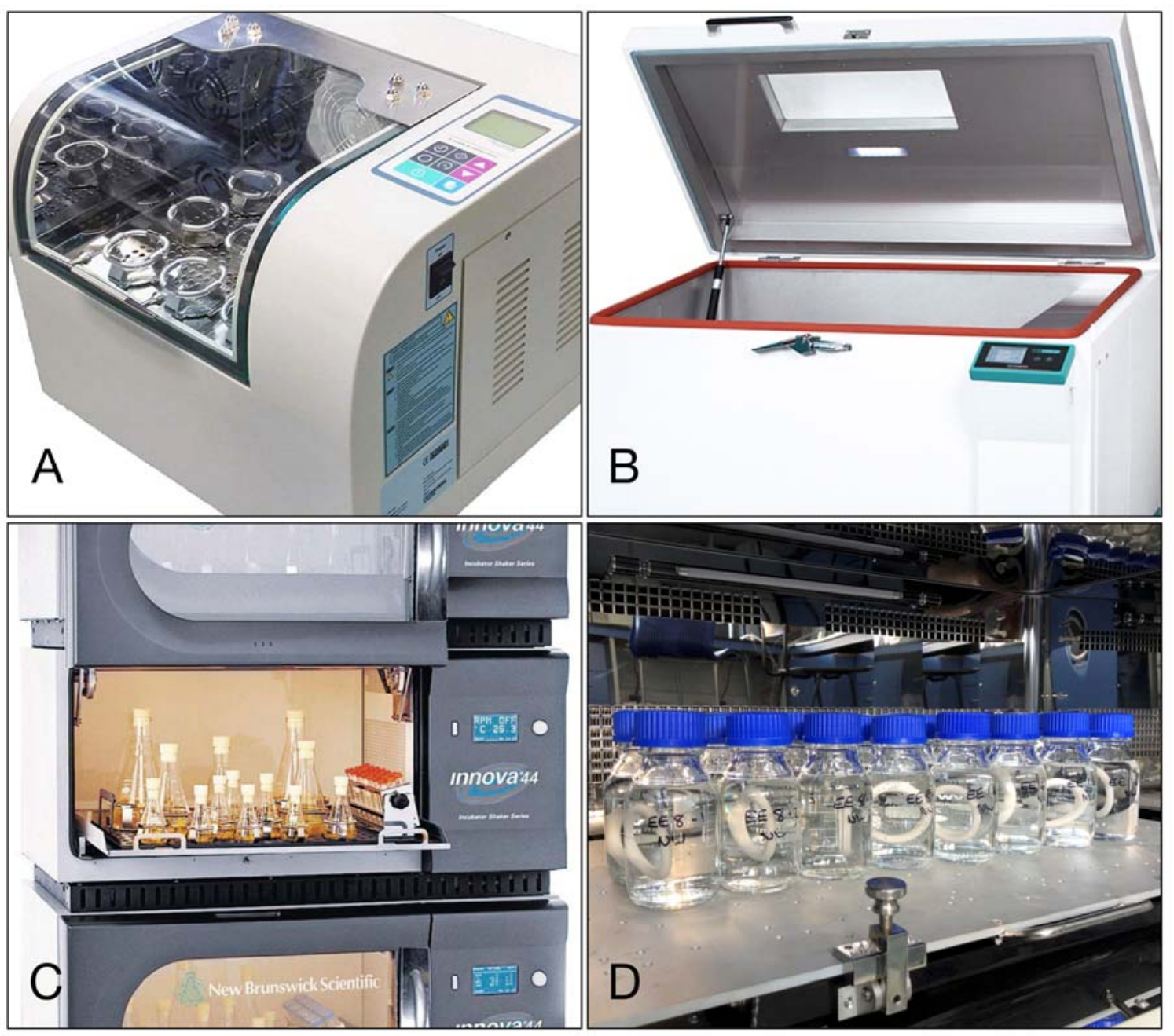

323 Fig. 3. Different type of shaking incubators commonly used for in vitro release testing of

324 vaginal rings. A - a benchtop shaking incubator; $\mathrm{B}-\mathrm{a}$ floor-standing top-opening orbital

325 shaking incubator; $\mathrm{C}$ - stackable orbital shaking incubators; D - flasks containing

326 suspended rings and stored in an orbital shaking incubator. 
329 A simple continuous flow-through apparatus has previously been reported for in vitro

330 release testing of matrix-type, core-type and sandwich-type silicone elastomer vaginal

331 rings containing the progestogens $\mathrm{D}(-)$-norgestrel, norethindrone or progesterone

$332[37,38,112]$. In general, the apparatus comprised (i) an isotonic saline solution, (ii) a

333 peristaltic pump, (iii) a glass flow cell containing the sample ring device and maintained

334 at $37^{\circ} \mathrm{C}$ by immersion in water bath, and (iv) a vessel to collect the saline solution

335 effluent. Flow rates in excess of $1000 \mathrm{~mL} /$ day were needed to maintain sink conditions,

336 and the experiments were run continually for up to 60 days. The in vitro release rates

337 were subsequently calculated based on the amount of progestogen present in a known

338 aliquot of the effluent and the total volume of effluent collected over a defined period of

339 time. Extraction and concentration of progestogen from the flow cell effluent was

340 performed by extracting the aliquot of effluent (usually $100 \mathrm{~mL}$ ) with methylene chloride

$341(10 \mathrm{~mL})$ containing a suitable internal standard, before quantitation of the progestogen

342 using gas chromatography. Using this method, similarity of progestogen in vitro release

343 rate was demonstrated for rings tested (i) immediately after manufacture, (ii) unused and

344 after two years storage, (iii) on day 10 of in vitro release testing, (iv) at the end of in

345 vitro release testing, and (v) after clinical testing of the ring.

\section{5.3. Reciprocating holder apparatus}

348 USP Apparatus 7 (reciprocating holder) is commonly used to test transdermal patch drug

349 products. However, the apparatus can also be applied to extended release tablets,

350 capsules, osmotic pumps, beads and arterial stents. There is only one report in the

351 literature describing use of this apparatus for vaginal ring testing. Externbrink et al.

352 described use of Apparatus 7 for accelerated in vitro release testing of Nuvaring ${ }^{\circledR}$ [104].

353 Ring segments, $1-1.5 \mathrm{~cm}$ in length and sealed with an acrylate glue that was 
354 impermeable to the steroid molecules to eliminate end effects, were placed into 50-mesh

355 basket holders within heated glass dissolution cells containing $10 \mathrm{~mL}$ vaginal fluid

356 simulant or water and experiments performed at temperatures of 44,50 and $55^{\circ} \mathrm{C}$.

\subsection{Rotating paddle apparatus}

359 Only one paper has reported use of a rotating paddle dissolution apparatus (Apparatus II)

360 for in vitro release testing of a vaginal ring device [58]. Here, the authors tested a

361 drosperinone-releasing silicone elastomer vaginal ring into $200 \mathrm{~mL}$ of $0.3 \%$ sodium

362 dodecyl sulfate (SDS) solution maintained at $37{ }^{\circ} \mathrm{C}$ and stirred at $50 \mathrm{rpm}$. The release

363 medium was replaced every $24 \mathrm{hr}$ over the 21-day study period. Drospirenone solubility

364 was determined to be $13.0 \mu \mathrm{g} / \mathrm{mL}, 12.1 \mu \mathrm{g} / \mathrm{mL}, 8.9 \mu \mathrm{g} / \mathrm{mL}, 15.2 \mu \mathrm{g} / \mathrm{mL}$, and 392.6

$365 \mu \mathrm{g} / \mathrm{mL}$ in pure water, $\mathrm{NaCl}$ solution, $\mathrm{PBS}(\mathrm{pH} 3.8), 0.03 \%$ SDS solution, and $0.3 \%$ SDS

366 solution, respectively. $200 \mathrm{~mL} 0.3 \%$ SDS medium was selected to maintain sink

367 conditions. Evaporative loss of the medium during release testing was not discussed in

368 the paper.

\section{6. Modelling of in vitro release data}

371 It is not the purpose of this review to provide a detailed overview of the various

372 mathematical models used to model the kinetics of in vitro drug release from vaginal

373 rings. However, the most commonly reported kinetic models used to assess data obtained

374 from the in vitro release testing of vaginal rings are briefly described.

376 All seven marketed vaginal rings are fabricated from thermoplastic polymers or silicone

377 elastomers. Five rings - Estring ${ }^{\circledR}$, Nuvaring ${ }^{\circledR}$, Femring $^{\circledR}$, Ornibel ${ }^{\circledR}$ and Annovera ${ }^{\circledR}$ - are

378 reservoir-type rings, while Fertiring ${ }^{\circledR}$ and Progering ${ }^{\circledR}$ are matrix-type rings. The 
379 dapivirine-releasing ring is also a matrix ring. The non-degradable and non-swellable

380 nature of these polymeric rings means that the incorporated drugs are released according

381 to a permeation-controlled mechanism (also commonly referred to as diffusion-

382 controlled mechanism). Thus, it is common to use the terms 'membrane-controlled

383 permeation' for reservoir/core rings, and 'matrix-controlled permeation' for matrix-type

384 rings. Regardless of the ring design, permeation-controlled drug release from a vaginal

385 ring requires at least three distinct mechanistic steps: (i) the incorporated drug must

386 dissolve to some extent in the polymer(s) used to fabricate the ring; (ii) the dissolved

387 drug molecules must then diffuse through the polymer(s); and (iii) upon reaching the

388 surface of the ring, the drug(s) must partition into the surrounding vaginal fluid/release

389 medium.

391 For matrix-type rings, in which the (usually) solid crystalline drug substance is dispersed

392 homogenously throughout the ring body, drug release under sink conditions normally

393 follows so-called 'root-time kinetics'. This is confirmed by a linear plot when the

394 cumulative release data is plotted against the square root of time. This model was first

395 introduced by Higuchi back in 1961 for release of drug from a thin ointment film into the

396 skin [113]. Based upon certain key assumptions, the two classical forms of the 'Higuchi

397 equation' can be derived (Eqs. 1 \& 2; Table 3) [114,115]. These equations have been

398 reported many times for modelling drug release from matrix-type vaginal rings

$399[41,49,55,62,64,65,89,92,95,116-122]$. Only one matrix-type vaginal ring device has

400 been reported containing a liquid drug at room temperature, and for which release

401 kinetics are significantly modified compared to matrix-type ring containing solid drugs

402 due to the absence of a drug depletion zone [56]. 
403 Table 3. Equations that have been used to model in vitro release data for matrix-type and 404 reservoir-type drug-releasing vaginal rings.

405

\begin{tabular}{|c|c|c|}
\hline Type of ring & Equations & References / Comments \\
\hline \multirow[t]{3}{*}{ Matrix-type rings } & Eq.1. $\frac{M_{t}}{A}=\sqrt{D C_{s}\left(2 C_{0}-C_{s}\right) t}$ & {$[113,114,123,124]$} \\
\hline & Eq.2. $\frac{M_{t}}{A}=\sqrt{D C_{S}\left(2 C_{0}\right) t}$ & $\begin{array}{l}\text { Simplified version of Eq.1 where } \\
C_{0} \gg>C_{s}\end{array}$ \\
\hline & Eq.3. $\quad M_{t}=k \sqrt{t}$ & {$[125]$} \\
\hline \multirow[t]{2}{*}{ Reservoir-type rings } & Eq.4. $M_{t}=\frac{\left(2 \pi C_{s} D L\right)}{\ln ^{b} / a} t$ & {$[33,36,126-128]$} \\
\hline & Eq.5. $\quad M_{t}=\frac{\left(C_{s} D A\right)}{h} t$ & {$[55]$} \\
\hline
\end{tabular}

By comparison, reservoir-type rings, comprising a drug-loaded core surrounded by a rate-contolling polymeric membrane, generally offer controlled release of drug(s) at a

410 near constant rate of release. Most often, the release rate is described in units of $\mu \mathrm{g} / \mathrm{day}$.

411 For example, Femring ${ }^{\circledR}$ provides release of estradiol-3-acetate at rates equivalent to

412 either 50 or $100 \mu \mathrm{g} /$ day estradiol for 3 months (Table 1). An entirely similar permeation-

413 controlled mechanism operates for reservoir rings, except that the drug-free membrane

414 material and/or thickness is judiciously selected to differ from that of the drug-loaded

415 core so as to control the drug release rate. For example, the drug-loaded core of

416 Nuvaring ${ }^{\circledR}$ is fabricated using an ethylene vinyl acetate (EVA) copolymer containing

$41728 \%$ vinyl acetate residues, while the rate-controlling EVA sheath contains only 9\%

418 vinyl acetate residues (Table 1). A reduction in the vinyl acetate content leads to lower

419 drug permeation rates, owing to increased proportion of impermeable crystalline

420 domains within the semi-crystalline EVA polymer [129]. By comparison, most 
421 reservoir-type silicone elastomer rings (e.g. Femring ${ }^{\circledR}$ and Estring ${ }^{\circledR}$ ) use the same

422 silicone elastomer material for fabrication of both the core and the membrane. Here, the

423 thickness of the membrane and the length of the drug loaded core control the observed

424 release rate.

426 Reservoir-type rings tested under sink conditions are usually characterised by linear

427 daily release vs. time plots (neglecting any initial lag or burst effects) and linear

428 cumulative release vs. time plots (Fig. 4), and follow 'zero-order' release kinetics.

429 Equations 4 and 5 (Table 3), in which the cumulative amount of drug release increases

430 proportionately with time, are commonly reported for the modelling of drug release from

431 reservoir-type rings.

\section{7. Risk of dose dumping}

434 With monolithic matrix-type vaginal rings where the drug is evenly dispersed throughout

435 the entire volume of the device, a natural drug burst is observed at the beginning of in

436 vitro release testing due to rapid release of drug close to the ring surface (Fig. 4A and

437 4C). This is due to the fact that drug at or near the surface of a matrix ring has a

438 relatively small diffusional pathway to overcome in order to be released. Even if a

439 matrix-type ring were to rupture in vivo, the increase in drug release rate would not likely

440 be clinically significant. 
MATRIX RINGS
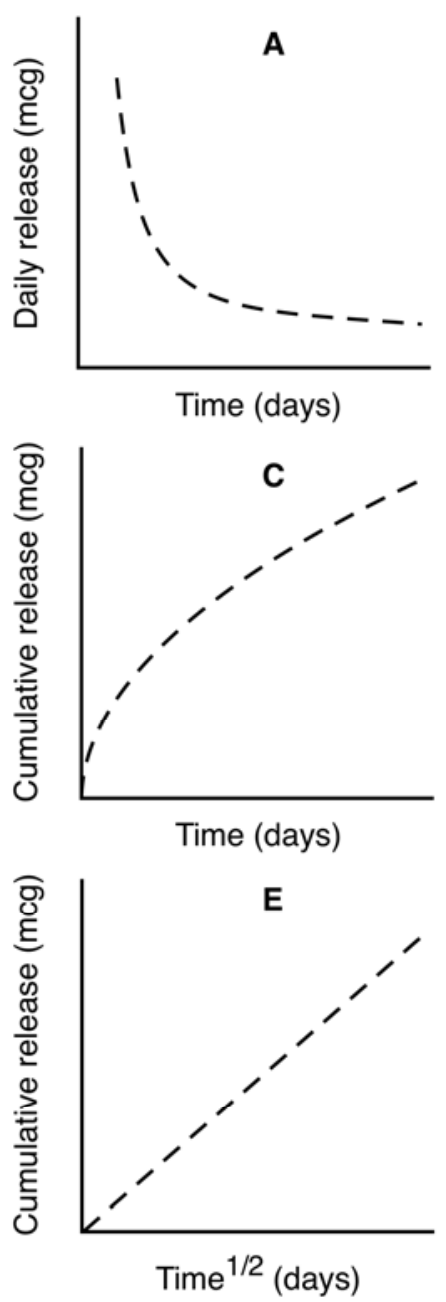

RESERVOIR RINGS
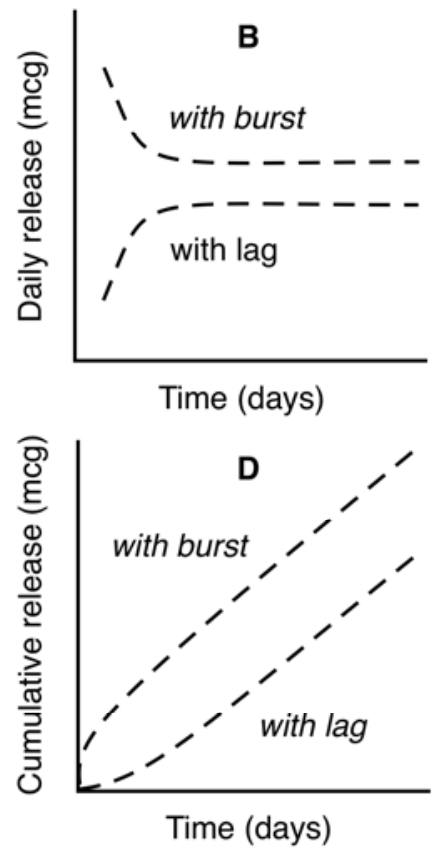

441

442 Fig. 4. Representative in vitro drug release vs. time profiles for matrix (A, C and E) and 443 reservoir-type vaginal rings (B and $\mathrm{D})$.

445 With reservoir or core-type vaginal rings, in which the drug(s) is located in one or more

446 reservoirs or cores encapsulated with a drug-free membrane or sheath, lag or burst

447 effects are often observed during the intial period of in vitro release testing (Fig. 4B and

448 4D). These effects are due to redistribution of the drug(s) within the ring caused by (i)

449 enahcned polymer solubilisation of the drug during high-temperature manufacture of the

450 rings, (ii) cooling and recrystallisation of the drug within the rings following

451 manufacture, and (ii) subsequent long-term storage of the ring product. 
453 In order to better capture data around initial lag and burst effects, it is becoming

454 increasingly common to include additional early sampling timepoints (e.g. 4, 8, $12 \mathrm{hr}$ )

455 during in vitro release testing of rings. Thereafter, the release medium is typically

456 sampled once daily (except weekends) for the first few weeks following initation of in

457 vitro release testing, and then less frequently (often once or twice weekly), ensuring sink

458 conditions are maintained throughout the duration.

460 Over and beyond these burst and lag effects, there is also a potential risk of dose

461 dumping with reservoir-type rings due to either defects introduced during manufacture or

462 in vivo rupture of the rate-controlling membrane. Admittedly, the risk is very low for

463 conventional reservoir-type rings containing polymeric cores (such as Estring ${ }^{\circledR}$,

$464 \quad$ Femring $^{\circledR}$ and Nuvaring ${ }^{\circledR}$ ) since (i) the methods of manufacture (injection molding and

465 extrusion) are highly reliable and robust, (ii) the rings are very unlikely to break under

466 even extreme conditions of compressive and tensile stress, and (iii) even in the event of a

467 break in the membrane, the drug in the exposed reservoir compartment would still be

468 released according to a permeation-controlled mechanism, albeit no longer conforming

469 to zero-order kinetics for at least a period of time. To date, there have been no reports or

470 other evidence of dose dumping in vivo with use of vaginal rings. Nonetheless,

471 regulatory agencies normally request in vitro release data for testing of vaginal rings in

472 which the drug containing core(s) has been artificially exposed by rupturing the

473 membrane. Introduction of flaws into the vaginal rings is also useful in demonstrating

474 the discriminating ability of the in vitro release method.

476 Three-layer reservoir-type thermoplastic vaginal rings offering controlled release of the

477 antidepressant drug mirtazapine or the antipsychotic drug risperidone have been tested 
478 for the risk of dose dumping by making a single cut through the ring cross-section,

479 thereby exposing two ring ends $[130,131]$. The in vitro drug release performances of the

480 cut rings were entirely similar to those of control rings that had not been cut.

482 In more robust testing of the potential risk of dose dumping, the Population Council's

483 NES+EE ring was cut to remove part of the rate-controlling membrane surrounding the

484 dug-loaded cores. In one experiment, a certain thickness of the silicone elastomer

485 membrane was removed without exposing the underlying drug-loaded cores, thereby

486 significantly shortening the drug diffusion path and increasing the in vitro release rate. In

487 another experiment, the membrane was removed to expose the cores within the ring

488 body. These configurations are useful in assessing the discriminating ability of the in 489 vitro release method (Bruce Variano; unpublished data).

\section{Accelerated in vitro release testing of vaginal rings}

492 A particular challenge with vaginal rings is the long time periods required for real-time

493 drug release testing. Compared to immediate release oral dosage forms for which

494 dissolution can often be completed in less than $1 \mathrm{~h}$, drug release from rings usually extends over many weeks or months (Table 1), with major implications for batch release and shelf-

496 life of the product. To overcome this time constraint, and in addition to real-time release

497 testing, quality control testing for extended, sustained or controlled release drug products

498 is often performed using accelerated in vitro release testing methods. This approach has

499 been successfully applied to a wide range of dosage forms through modification of the test 500 conditions, such as increasing temperature, adjusting the $\mathrm{pH}$ of the release medium, using 501 solvent-based release media, adding surfactants to aqueous release media, or adjustment 502 of the agitation rate $[11,50,132-135]$. However, to date, there have been only two reports 
503 in the literature of accelerated release testing of a vaginal ring device using elevated 504 temperature conditions, solvent+water mixtures (ethanol, isopropanol or acetonitrile), or 505 both $[49,104]$.

507 Accelerated testing methods (which must also be discriminating and, if possible,

508 clinically relevant) should provide a distinct in vitro release profile in which at least $80 \%$

509 of the initial drug load has been released. Ideally, drug release in both real-time and

510 accelerated tests should follow the same release mechanism with a 1:1 correlation

511 between the release profiles. However, in practice, the release mechanism may change if

512 the physical properties of the ring change upon exposure to the accelerated condition.

513 Conducting in vitro release at elevated temperature typically leads to an increased rate of

514 release without change to the mechanism, due to an increase in the permeation

515 coefficient of the drug in the polymer. Use of high concentrations of organic solvents in

516 the release medium, however, may lead to changes in the underlying release mechanism,

517 for example from a permeation control mechanism (where the rate-limiting step is

518 diffusion of the polymer-dissolved drug through the polymer) to an extraction-type

519 mechanism involving solvent influx into the ring, swelling of the ring polymer, and for

520 which the rate limiting step is the solubility of the drug in the medium. Accelerated in

521 vitro release testing of vaginal ring devices is only valuable in limited cases and with the

522 understanding that a correlation to real-time drug release may not, and likely will not, be 523 achievable.

\section{9. In vitro-in vivo correlations and relationships}


527 In vitro-in vivo correlations (IVIVCs) are correlations between in vitro and in vivo data

528 that support subsequent prediction of in vivo results based on measured in vitro data

529 [136-139]. According to the FDA definition of IVIVC, the in vitro data usually takes the

530 form of the rate or extent of drug dissolution or release, while the in vivo response is

531 commonly plasma drug concentrations or the amount of drug absorbed [140]. The USP

532 define IVIVC is similar but somewhat broader in its interpretation, extending the in vivo

533 data to a "biological property produced by a dosage form", and the in vitro data as "a

534 physicochemical property or characteristic" of the dosage form [141].

536 9.2. In vitro-in vivo relationships

537 By comparison, in vitro-in vivo relationships (IVIVRs) are semi-quantitative or rank-

538 order relationships between in vitro release data and an in vivo outcome (e.g. blood

539 levels of the drug or the amount of drug absorbed) [142-144]. As such, IVIVRs are not

540 considered as robust as IVIVCs. However, if a qualitative relationship can be established

541 between in vitro release rate and in vivo absorption, then the in vitro release rate method

542 may be deemed clinically relevant and therefore a safe space can be built via bracketing

543 approach. Subsequent major changes whose dissolution profiles fall within this safe

544 space are considered bioequivalent [145].

\section{9.3. IVIVCs and IVIVCs for vaginal rings}

547 Given the focus of this review article on in vitro release testing methods for vaginal

548 rings, it is worth taking time to consider the role of these methods in developing

549 IVIVCs/IVIVRs for vaginal rings. IVIVCs are most commonly used by pharmaceutical

550 companies to justify bioequivalence waivers for formulation changes (excipients, dosage

551 strengths, etc.) without in vivo data, and are increasingly recommended by regulatory 
552 authorities in order to demonstrate product understanding. Although in vitro release

553 testing has been used extensively as a quality control tool for testing and comparing

554 vaginal ring formulations, predictions of in vivo performance from in vitro release data

555 are either rarely performed, or at least are rarely reported in the literature. Two

556 contributing factors may help explain the scarcity of IVIVCs for ring products. First,

557 IVIVCs require a validation step based on clinical studies (e.g. bioavailability

558 /bioequivalence studies), which are expensive and typically require multiple developed

559 formulations showing different release profiles in multiple media [146]. Second, other

560 drug dosage forms (and particularly oral dosage forms) are typically more lucrative than

561 vaginal rings, such that there is a financial component/incentive to develop IVIVCs,

562 since line extensions (different strengths, more efficient manufacturing, etc.) will often

563 be developed after initial product approval. The use of non-compendial apparatus and

564 methods for in vitro release testing of vaginal rings, the often very poor water solubility

565 of drugs formulated in vaginal rings, the relatively long duration of release offered by

566 vaginal rings, and the use of non-biorelevant release media may also contribute to the

567 lack of good predictive models.

569 However, for non-oral or locally acting (i.e. not systemically absorbed) drug products,

570 including vaginal rings, establishing IVIVCs is often challenging due to the complexities

571 of the formulations, the the lack of standardized compendial in vitro release testing

572 methods, and significant inter-patient variability in pharmacokinetic data [72,147]. For

573 example, the first IVIVC for a marketed transdermal drug delivery system (a drug-in-

574 adhesive type estradiol-releasing transdermal patch offering multiple drug delivery rates)

575 has only been reported within the past five years [148]. In the context of vaginal ring 
research, the most anticipated use of IVIVC is to support biowaivers for manufacturing and non-compendial excipient changes.

\subsection{Different levels of IVIVC}

The FDA defines four main levels of IVIVC, depending upon the type of data used to establish the relationship and the ability of the correlation to predict the complete plasma profile of a dosage form $[140,147,149]$. A Level A correlation represents a point-to-point relationship (usually linear) between an in vitro release performance measure and an in vivo response measure over the entire time course of both studies. The FDA define Level A correlations as: "A predictive mathematical model for the relationship between the entire in vitro dissolution/release time course and the entire in vivo response time course, e.g., the time course of plasma drug concentration or amount of drug absorbed" [140]. For a vaginal ring device, the daily in vitro release vs. time and the plasma, vaginal fluid and vaginal tissue drug concentration vs. time data are likely to be most useful in establishing the correlation (Fig. 4), the latter twomore so for drug products intended to act locally. For a matrix-type vaginal ring containing excess solid drug dispersed throughout the ring body and offering $\mathrm{t}^{1 / 2}$ release kinetics (Fig. 4), plasma concentrations are anticipated to decline with time, in line with the declining daily in vitro release values $[7,55,64,66]$. It should be noted that for rings releasing very low quantities of drug such that plasma levels are extremely low and highly variable (e.g. the dapivirine-releasing matrix-type vaginal ring [150-153], any potential correlation may be lost in the noise. For reservoir-type rings, which offer near-constant daily in vitro release rates, plasma concentrations are observed to remain almost constant or to decline slowly with time $[30,36,154]$. Certain practical difficulties can arise with attempting Level A correlations for vaginal rings, including: (i) the requirement to support extended 
601 measurement of in vivo drug concentrations over periods of many weeks or months; (ii)

602 variations in in vivo drug concentrations among ring users due to physiological factors,

603 such as vaginal $\mathrm{pH}$, vaginal microbiome, body mass index, age, etc. 
Matrix-type vaginal rings

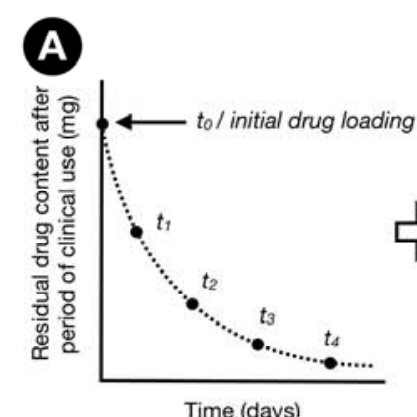

0

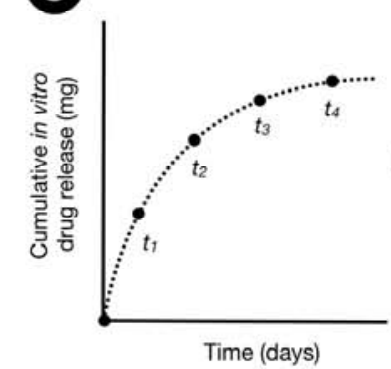

B

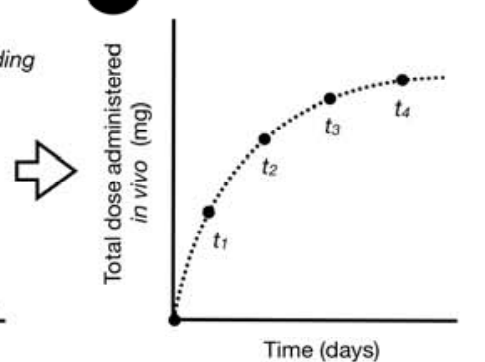

o

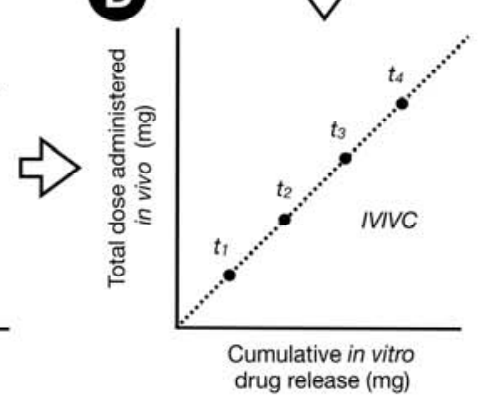

Reservoir-type vaginal rings
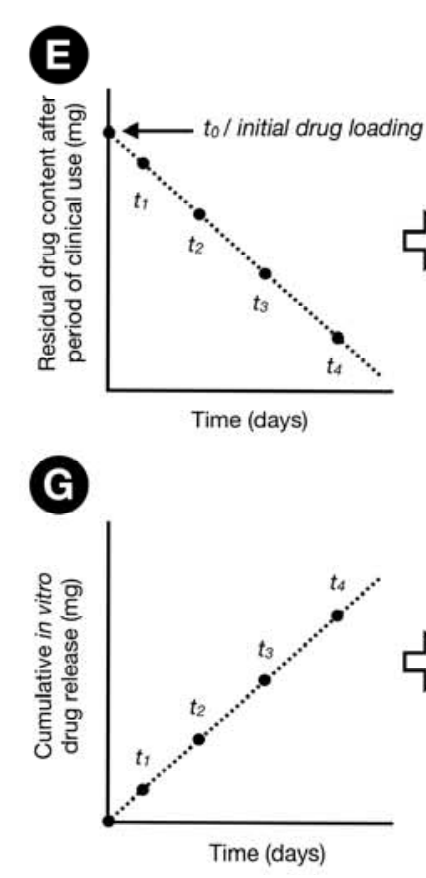

F

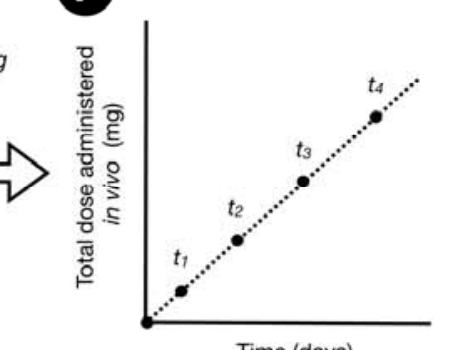

$\boldsymbol{\oplus}$

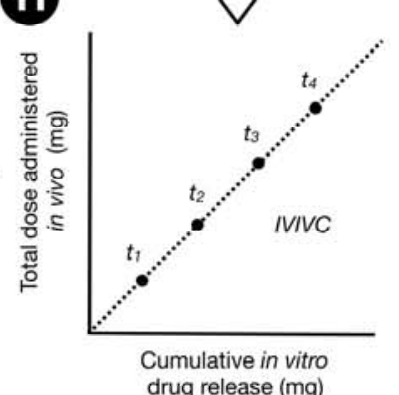

605

606 Fig. 5. Workflows describing methods for developing IVIVCs for matrix-type (A-D) and reservoir-type vaginal rings (E-H), where the in vivo

607 parameter is the total dose administered at any time $t$. This dose is calculated by subtracting the value for the residual drug content in the ring

608 after a specified period of clinical use (based on a solvent extraction method) from the value of the initial drug loading in the ring. Panels I and $\mathrm{J}$

609 illustrate other possible correlations based on use of either plasma AUC or measured drug concentration in a biological medium (usually plasma,

610 vaginal tissue or vaginal fluid) as the readout for the in vivo parameter. 
611 For the contraceptive vaginal ring product Nuvaring ${ }^{\circledR}$, an IVIVC with a level A

612 correlation was successfully established, determined predictive for in vivo performance

613 and thus accepted as a basis for obtaining in vivo bioequivalence waivers [155].

615 Level B correlations, like those of Level A, make use of all of the in vitro and in vivo 616 data, but are not considered to be point-to-point correlations. Instead, a Level B IVIVC 617 uses the principles of statistical moment analysis. The FDA define Level B correlations

618 as: "A predictive mathematical model for the relationship between summary

619 parameters that characterize the in vitro and in vivo time courses, e.g., models that

620 relate the mean in vitro dissolution time to the mean in vivo dissolution time, the mean in

621 vitro dissolution time to the mean residence time in vivo, or the in vitro dissolution rate 622 constant to the absorption rate constant" [140]. Typically, the mean in vitro dissolution

623 time is compared either to the mean residence time (MRT) or to the mean in vivo

624 dissolution time. Level B correlations do not uniquely reflect the actual in vivo plasma

625 level curve, because a number of different in vivo curves will produce similar mean

626 residence time values [138]. Level B correlations are least useful for regulatory purposes, 627 are rarely encountered even for new drug applications (NDAs) for oral dosage forms and 628 have never been reported for vaginal rings.

630 A Level C correlation establishes a single point relationship between a

631 dissolution/release parameter and a pharmacokinetic parameter. The FDA definition is as 632 follows: "A predictive mathematical model of the relationship between the amount 633 dissolved in vitro at a particular time (or the time required for in vitro dissolution of a 634 fixed percent of the dose, e.g., T50\%) and a summary parameter that characterizes the in 635 vivo time course (e.g., $C_{\max }$ or $\left.A U C\right)$ )" [140]. In the context of vaginal rings, the in vitro 
636 parameter would typically be the daily release rate, while the in vivo parameter could be

637 selected from plasma measurements over time - area under the curve (AUC), maximum

638 plasma/serum concentration $\left(C_{\max }\right)$ or time to maximum concentration $\left(T_{\max }\right)$. Single

639 point Level C correlations are not considered useful to IVIVC of vaginal ring products

640 and are not acceptable to regulatory agencies, however, multiple point, Level C

641 correlations may be used to justify a biowaiver provided the correlation is established

642 over the entire dissolution profile with one or more pharmacokinetic parameters of

643 interest. Level C correlations are particularly useful in the early stages of formulation

644 development when different formulations are being tested.

646 According to best practice, the development of IVIVC requires in vivo pharmacokinetic

647 (PK) data with at least three different drug dissolution/release rates for the

648 pharmaceutical product. In principle, this is relatively easy to achieve for many vaginal

649 ring devices. For example, adjusting the drug loading in a matrix-type ring will

650 effectively modulate the release rate $[17,55,64,66,156]$. For reservoir-type rings,

651 adjusting either the length of the internal drug-loaded reservoir or the thickness of the

652 rate-controlling membrane will effectively modulate the release rate $[17,36,64,128]$. For

653 pod-type rings, the drug release rate can be adjusted either by changing the number of

654 pods included in the ring body or by modifying the design characteristics of the delivery

655 channel $[21,25]$. In practice, however, it is very unusual for a company to develop and

656 market vaginal ring products offering different release rates. Femring ${ }^{\circledR}$ is the exception,

657 with two different release rates available $(50 \mu \mathrm{g} /$ day and $100 \mu \mathrm{g} /$ day estradiol, Table 1$)$.

659 IVIVCs have not been attempted for antiretroviral-releasing vaginal rings for HIV

660 prevention. In order to be clinically effective, the antiretroviral drug(s) needs to be 
661 released from the ring device at sufficient rate to maintain the concentrations of drug in

662 the vaginal fluid and/or vaginal tissue above a minimum protective level. For this reason,

663 IVIVC studies are not considered, since there is no clinical rationale for commercialising

664 anything but a single formulation type having an efficacious release rate. Moreover, in

665 late-stage efficacy trials of antiretroviral-releasing rings, low dosing would increase the

666 risk of HIV acquisition, and high dosing would likely increase the extent of systemic

667 absorption and potentially drive the emergence of resistant strains of the virus in users

668 who became infected while using the product.

669

670 The development and testing of different drug release rates for steroid-releasing vaginal

671 rings for hormone replacement therapy or contraception is equally challenging from an

672 IVIVC perspective. In general, contraceptive rings are developed to release drug(s) at a

673 single clinically-relevant rate, as exemplified by Nuvaring and Annovera (Table 1). The

674 fact that only one release rate may be required is not a limitation for developing an

675 IVIVC. The situation is somewhat different for rings used for estrogen replacement

676 therapy, where different rates of estrogen administration may be beneficial. For example,

677 Femring (but not Estring) is supplied in two strengths (50 and $100 \mu \mathrm{g} /$ day, Table 1).

678 With this product, therapy is started at the lowest effective dose and the shortest duration

679 consistent with treatment goals, and dosage adjustment is guided by the clinical

680 response.

681

682 9.5. Literature examples of IVIVCs and IVIVRs for vaginal rings

683 One of the earliest reports of an IVIVC for an experimental vaginal ring was reported for

684 ethynodiol diacetate-releasing silicone elastomer devices implanted in rabbits, in which

685 both the plasma drug concentrations of norethindrone (a major metabolite of ethynodiol 
686 diacetate) and the cumulative amount of drug released in vivo were correlated with the in 687 vitro release rates obtained under three hydrodynamic conditions [59]. Due to the small

688 size of the rabbit vagina relative to that of women, the test devices comprised $1 \mathrm{~cm}$ 689 sections cut from rings designed for use in women. In vitro release experiments were 690 conducted with similar devices into a $75 \%$ polyethylene glycol 400 aqueous solution (to 691 provide sink conditions) at each of 0,30 and $81 \mathrm{rpm}$ rotational speeds. The cumulative 692 amount of ethynodiol diacetate released in vivo was obtained by determining the residual 693 drug content (by extraction with methanol) after different durations of implantation. The 694 measured in vivo release rate of $2.10 \mathrm{mg} / \mathrm{cm}^{2} / \mathrm{day}^{0.5}$ was noted to lie between the in vitro 695 release rates obtained for the rings tested under the 30 and $81 \mathrm{rpm}$ conditions.

697 Timmer et al. have reported that in vivo release rates were in good agreement with in 698 vitro release rates for silicone elastomer, reservoir-type, combination contraceptive 699 vaginal rings offering controlled release of 3-keto-desogestrel (also known as 700 etonogestrel) and ethinyl estradiol [157]. In fact, these rings were early prototypes for 701 Nuvaring ${ }^{\circledR}$ (Table 1). Three different ring formulation were tested, offering mean daily 702 release rates of 75,100 or $150 \mu \mathrm{g}$ /day etonogestrel and $15 \mu \mathrm{g} /$ day ethinyl estradiol. The

703 results from the study demonstrated (i) that in vitro release characteristics were

704 independent of the conditions used, and (ii) a linear relationship between the in vitro 705 release rates and the in vivo absorption rates for both drug molecules. Even though the 706 results did not strictly meet the criteria outlined in the IVIVC guidance, the IVIVC was 707 deemed acceptable due to the complex nature of the dosage form. The sponsor 708 subsequently changed the batch size, the manufacturing process, and the amount of non709 controlling excipients. Although these changes would normally require a bioequivalence 710 study, the IVIVC was deemed acceptable and the changes were approved [137]. 
712 As part of study to develop a 90-day progesterone-releasing vaginal ring for use in

713 postpartum contraception, Landgren et al. have reported a direct correlation between

714 plasma progesterone levels (areas under curves) and in vitro release rates for rings

715 offering three different initial release rates $(5,8$ and $20 \mathrm{mg} / \mathrm{day})$ [158]. In a follow-on

716 clinical study, significantly higher concentrations of pregnanediol glucuronide - a major

717 progesterone metabolite excreted in the urine - were measured for the $20 \mathrm{mg} /$ day ring

718 compared to the $5 \mathrm{mg} /$ day ring [159].

719

720 Clark et al. makes reference to poor IVIVC in preliminary pharmacokinetic studies

721 testing a UC781-loaded silicone elastomer matrix-type ring in pig-tailed macaques [160].

722 However, the actual data was never published. UC781 is an experimental non-nucleoside

723 reverse transcriptase inhibitor that had previously been considered as a HIV microbicide

$724[119,161,162]$.

725

726 Johnson et al. have reported a polyurethane vaginal rings offering sustained release of

727 the experimental antiretroviral compounds IQP-0528 and IQP- 0532 [163]. The paper

728 describes in vitro release testing of the rings under both sink and non-sink conditions and

729 pharmacokinetic assessment in pig-tailed macaques. A simple in vivo correlation was

730 established between the drug levels measured in the vaginal fluid and the total amount of

731 the drugs administered in vivo during the 28-day pharmacokinetic study (as measured by

732 post-use solvent extraction). Although an IVIVC was not considered in the paper, the

733 authors noted that the cumulative percentages of the two drugs released under in vitro

734 non-sink conditions were similar to those observed in vivo, whereas in vitro testing using

735 a sink condition release medium overestimated release of the drugs. 
737 McConville et al. reported the lack of an IVIVC in macaques for a matrix-type silicone

738 elastomer vaginal ring releasing the very poorly water-soluble experimental

739 antiretroviral drug UC781 [119]. However, once again, this was not an IVIVC. Different

740 sizes of rings, suitable for use in macaques and humans, were tested for in vitro release

741 using sink condition model $(100 \mathrm{~mL}$ daily of $1: 1 \mathrm{v} / \mathrm{v}$ ethanol/water, $1: 1 \mathrm{v} / \mathrm{v}$

742 isopropanol/water or $1 \% \mathrm{w} / \mathrm{v}$ aqueous benzalkonium chloride solution). Residual drug

743 content values in rings initially loaded with $100 \mathrm{mg}$ UC781 were measured after both 28 -

744 day vaginal placement in pig-tailed macaques and in vitro release testing. The results

745 showed 10-times less drug release in vivo compared to in vitro, which was attributed to

746 the limited solubility of UC781 in the aqueous vaginal fluid. Although the authors to not

747 comment on this issue, it is assumed that adjustment of the composition of the in vitro

748 release medium (to decrease its solvating power) would be useful in modulating the in

749 vitro release to more closely mimicking in vivo release.

751 Moss et al. have reported in vivo release rate divided by in vitro release rate as a measure 752 of IVIVR following pharmacokinetic testing of pod-type vaginal rings in macaques and

753 sheep $[21,46]$. The in vitro release rate was obtained from the slope of the in vitro

754 cumulative release vs. time profile. The in vivo release rates were based on the residual

755 drug mass remaining in the rings following in vivo use and the assumption, supported by

756 in vitro data, that drug release was linear over the test period. The calculated IVIVCs for

757 a range of antiretroviral drugs (including tenofovir disoproxil fumarate, maraviroc

758 and emtricitabine) ranged between $0.2-0.7$. It should be noted that the release profile

759 does not have to be linear for a successful IVIVC/IVIVR, and the absorption profile in

760 the vaginal vault may not be the same for every woman. 
762 Matrix-type rings containing dapivirine or progesterone [41,164] and reservoir-type and

763 sandwich-type silicone elastomer rings containing progesterone, d-norgestrel or

764 norethindrone [112] have been shown to provide estimated in vivo release rates (based

765 on measurement of post-use analysis of residual drug content and assuming a constant

766 release rate) that were not significantly different from measured in vitro release rates.

767

768 Finally, a physiologically-based pharmacokinetic model - the structural compartments of

769 which comprise the vaginal epithelium, vaginal stroma, lungs, liver and the rest of body

770 - has recently been reported for quantitative prediction of cervicovaginal tissue and

771 plasma concentrations for the 25 mg matrix-type dapivirine vaginal ring (Ring-004,

772 Table 1) [165]. (Fig. 5). Physiologically-based models may offer certain advantages over

773 more conventional approaches, including the potential to model the effect of

774 manufacturing changes, thereby allowing a potential better/easier prediction of in vivo

775 release rate. 


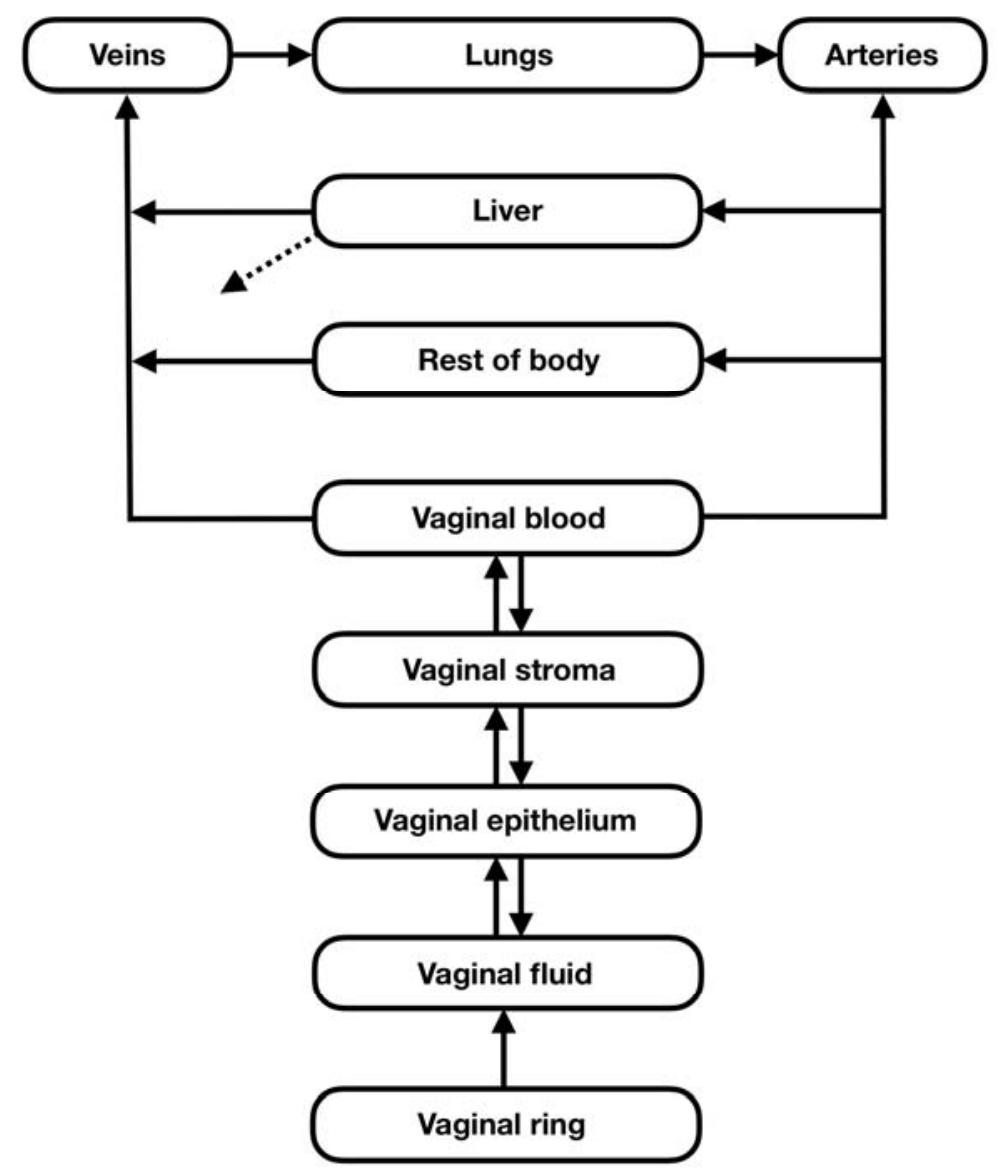

777 Fig. 5. Structural compartments of a physiologically-based pharmacokinetic model for a 778 drug-releasing vaginal ring. Figure adapted from (Kay et al., 2018).

\section{Conclusions}

781 Interest in vaginal ring technology for long-acting drug administration is growing, with

782 seven products currently marketed and a raft of new products in preclinical and clinical

783 development. In the continued absence of a compendial method for in vitro release

784 testing of vaginal rings, there will likely remain significant variations in the apparatus

785 and methods used for in vitro release testing of drug-releasing vaginal ring products. The

786 methods described and referenced in this review, however, should prove useful for

787 developers of new ring formulations. Further progress in the vaginal ring field and the 
788 development of biopredictive in vitro drug release methods will help focus efforts

789 towards the development of IVIVCs/IVIVRs.

\section{Acknowledgements}

792 The contributions of DM, CMcC, YB and PS to the article were supported by the

793 International Partnership for Microbicides (IPM), through the generous support from the

794 Ministry of Foreign Affairs of the Netherlands and the American people through the

795 United States Agency for International Development (USAID) in partnership with the

796 President's Emergency Plan for AIDS Relief (PEPFAR).

\section{Disclosure of interests}

799 PS is an employee of the International Partnership for Microbicides (IPM), owner and

800 developer of various vaginal ring products, including the dapivirine ring. BV is an

801 employee of the Population Council, developer of the Annovera ${ }^{\circledR}$ vaginal ring and with

802 interests in other vaginal ring products. $\mathrm{KM}$ and $\mathrm{PB}$ have received research funding from

803 both IPM and the Population Council.

804

805 Disclaimer

806 The views expressed here are the personal views of the authors and do not necessarily

807 represent the views of their respective organisations. 
809 [1] R.K. Malcolm, P.J. Boyd, C.F. McCoy, D.J. Murphy, Microbicide vaginal rings: Technological challenges and clinical development, Adv. Drug Deliv. Rev. 103 (2016) 33-56. doi:10.1016/j.addr.2016.01.015.

[2] R.K. Malcolm, K.-L. Edwards, P. Kiser, J. Romano, T.J. Smith, Advances in microbicide vaginal rings, Antiviral Res. 88 (2010) S30-S39. doi:10.1016/j.antiviral.2010.09.003.

[3] R.K. Malcolm, S.M. Fetherston, C.F. McCoy, P. Boyd, I. Major, Vaginal rings for delivery of HIV microbicides., Int. J. Womens. Health. 4 (2012) 595-605. doi:10.2147/IJWH.S36282.

[4] A. Thurman, M. Clark, J. Hurlburt, G. Doncel, Intravaginal rings as delivery systems for microbicides and multipurpose prevention technologies, Int. J. Womens. Health. 5 (2013) 695. doi:10.2147/IJWH.S34030.

[5] G.W. Duncan, Medicated Devices and Methods, US3545439 A, 1970.

[6] C.K. Brown, H.D. Friedel, A.R. Barker, L.F. Buhse, S. Keitel, T.L. Cecil, J. Kraemer, J.M. Morris, C. Reppas, M.P. Stickelmeyer, C. Yomota, V.P. Shah, FIP/AAPS joint workshop report: dissolution/in vitro release testing of novel/special dosage forms, AAPS PharmSciTech. 12 (2011) 782-794. doi:10.1208/s12249-011-9634-х.

[7] C.F. McCoy, D.J. Murphy, P. Boyd, T. Derrick, P. Spence, B. Devlin, R.K. Malcolm, Packing polymorphism of dapivirine and its impact on the performance of a dapivirine-releasing silicone elastomer vaginal ring, J. Pharm. Sci. 106 (2017) 2015-2025. doi:10.1016/j.xphs.2017.04.026.

[8] D.J. Murphy, C.F. McCoy, P. Boyd, T. Derrick, P. Spence, B. Devlin, R.K. Malcolm, Drug stability and product performance characteristics of a dapivirinereleasing vaginal ring under simulated real-world conditions, Int. J. Pharm. 565 (2019) 351-357. doi:10.1016/j.ijpharm.2019.05.027.

[9] C.F. McCoy, B.G. Millar, D.J. Murphy, W. Blanda, B. Hansraj, B. Devlin, R.K. Malcolm, P. Boyd, Mechanical testing methods for drug-releasing vaginal rings, Int. J. Pharm. 559 (2019) 182-191. doi:10.1016/j.ijpharm.2019.01.026.

[10] J.W. McBride, P. Boyd, N. Dias, D. Cameron, R.E. Offord, O. Hartley, V.L. Kett, R.K. Malcolm, Vaginal rings with exposed cores for sustained delivery of the HIV CCR5 inhibitor 5P12-RANTES, J. Control. Release. 298 (2019) 1-11. doi:10.1016/j.jconrel.2019.02.003.

[11] J.-M. Aiache, N. Aoyagi, D. Bashaw, C.K. Brown, W. Brown, D. Burgess, P. DeLuca, R. Djerki, J. Dressman, T. Foster, K. Gjellan, V. Gray, A. Hussain, T. Ingallinera, J. Klancke, J. Kraemer, H. Kristensen, K. Kumi, M. MuellerZsigmondy, N. Okafo, L. Ouderkirk, S. Parsi, S. Qureshi, M. Siewert, J. Dressman, C.K. Brown, V.P. Shah, J.-M. Aiache, N. Aoyagi, D. Bashaw, C.K. Brown, W. Brown, D. Burgess, J. Crison, P. DeLuca, R. Djerki, J. Dressman, T. Foster, K. Gjellan, V. Gray, A. Hussain, T. Ingallinera, J. Klancke, J. Kraemer, H. Kristensen, K. Kumi, C. Leuner, J. Limberg, P. Loos, L. Margulis, P. Marroum, H. Moeller, B. Mueller, M. Mueller-Zsigmondy, N. Okafo, L. Ouderkirk, S. Parsi, S. Qureshi, J. 
to dissolution / in vitro releasetesting of novel / special dosage forms, AAPS PharmSciTech. 4 (2003) 1-10. doi:10.1208/pt040107.

[12] S.A. Qureshi, Developing discriminatory drug dissolution tests and profiles: Some thoughts for consideration on the concept and its interpretation, Dissolution Technol. 13 (2006) 18-23. doi:10.14227/DT130406P18.

[13] J.A. Moss, A.M. Malone, T.J. Smith, S. Kennedy, C. Nguyen, K.L. Vincent, M. Motamedi, M.M. Baum, Pharmacokinetics of a multipurpose pod-intravaginal ring simultaneously delivering five drugs in an ovine model, Antimicrob. Agents Chemother. 57 (2013) 3994-3997. doi:10.1128/AAC.00547-13.

[14] S.R. Ugaonkar, A. Wesenberg, J. Wilk, S. Seidor, O. Mizenina, L. Kizima, A. Rodriguez, S. Zhang, K. Levendosky, J. Kenney, M. Aravantinou, N. Derby, B. Grasperge, A. Gettie, J. Blanchard, N. Kumar, K. Roberts, M. Robbiani, J.A. Fernández-Romero, T.M. Zydowsky, A novel intravaginal ring to prevent HIV-1, HSV-2, HPV, and unintended pregnancy, J. Control. Release. 213 (2015) 57-68. doi:10.1016/j.jconrel.2015.06.018.

[15] J.T. Clark, M.R. Clark, N.B. Shelke, T.J. Johnson, E.M. Smith, A.K. Andreasen, J.S. Nebeker, J. Fabian, D.R. Friend, P.F. Kiser, Engineering a segmented dualreservoir polyurethane intravaginal ring for simultaneous prevention of HIV transmission and unwanted pregnancy, PLoS One. 9 (2014) e88509. doi:10.1371/journal.pone.0088509.

[16] T.J. Johnson, K.M. Gupta, J. Fabian, T.H. Albright, P.F. Kiser, Segmented polyurethane intravaginal rings for the sustained combined delivery of antiretroviral agents dapivirine and tenofovir, Eur. J. Pharm. Sci. 39 (2010) 203-212. doi:10.1016/j.ejps.2009.11.007.

[17] Y. Wang, P. Boyd, A. Hunter, R.K. Malcolm, Intravaginal rings for continuous lowdose administration of cervical ripening agents, Int. J. Pharm. 549 (2018) 124-132. doi:10.1016/j.ijpharm.2018.07.053.

[18] A.B. Kimball, E. Javorsky, E.S. Ron, W. Crowley,, R. Langer, A novel approach to administration of peptides in women: Systemic absorption of a GnRH agonist via transvaginal ring delivery system, J. Control. Release. 233 (2016) 19-28. doi:10.1016/j.jconrel.2016.04.035.

[19] D.R. Friend, Intravaginal rings: controlled release systems for contraception and prevention of transmission of sexually transmitted infections, Drug Deliv. Transl. Res. 1 (2011) 185-193. doi:10.1007/s13346-011-0024-4.

[20] P.F. Kiser, T.J. Johnson, J.T. Clark, State of the art in intravaginal ring technology for topical prophylaxis of HIV infection., AIDS Rev. 14 (2012) 62-77. http://www.ncbi.nlm.nih.gov/pubmed/22297505.

[21] J.A. Moss, P. Srinivasan, T.J. Smith, I. Butkyavichene, G. Lopez, A.A. Brooks, A. Martin, C.T. Dinh, J.M. Smith, M.M. Baum, Pharmacokinetics and preliminary safety study of pod-intravaginal rings delivering antiretroviral combinations for HIV prophylaxis in a macaque model, Antimicrob. Agents Chemother. 58 (2014) 5125-5135. doi:10.1128/AAC.02871-14.

[22] C. Zhao, M. Gunawardana, F. Villinger, M.M. Baum, M. Remedios-Chan, T.R. Moench, L. Zeitlin, K.J. Whaley, O. Bohorov, T.J. Smith, D.J. Anderson, J.A. Moss, Pharmacokinetics and Preliminary Safety of Pod-Intravaginal Rings Delivering the Monoclonal Antibody VRC01-N for HIV Prophylaxis in a Macaque 
Model, Antimicrob. Agents Chemother. 61 (2017) e02465-16. doi:10.1128/AAC.02465-16.

[23] J.W. McBride, R. Karl Malcolm, N. Dias, D. Cameron, R.E. Offord, O. Hartley, V.L. Kett, B. Devlin, P. Boyd, Development and pharmacokinetics of a combination vaginal ring for sustained release of dapivirine and the protein microbicide 5P12-RANTES, Int. J. Pharm. 564 (2019) 207-213. doi:10.1016/j.ijpharm.2019.04.040.

[24] R.J. Morrow, A.D. Woolfson, L. Donnelly, R. Curran, G. Andrews, D. Katinger, R.K. Malcolm, Sustained release of proteins from a modified vaginal ring device, Eur. J. Pharm. Biopharm. 77 (2011) 3-10. doi:10.1016/j.ejpb.2010.10.010.

[25] M.M. Baum, I. Butkyavichene, J. Gilman, S. Kennedy, E. Kopin, A.M. Malone, C. Nguyen, T.J. Smith, D.R. Friend, M.R. Clark, J.A. Moss, An intravaginal ring for the simultaneous delivery of multiple drugs, J. Pharm. Sci. 101 (2012) 2833-2843. doi:10.1002/jps.23208.

[26] M.M. Baum, I. Butkyavichene, S.A. Churchman, G. Lopez, C.S. Miller, T.J. Smith, J.A. Moss, An intravaginal ring for the sustained delivery of tenofovir disoproxil fumarate., Int. J. Pharm. 495 (2015) 579-587. doi:10.1016/j.ijpharm.2015.09.028.

[27] N. Derby, M. Aravantinou, J. Kenney, S.R. Ugaonkar, A. Wesenberg, J. Wilk, L. Kizima, A. Rodriguez, S. Zhang, O. Mizenina, K. Levendosky, M.L. Cooney, S. Seidor, A. Gettie, B. Grasperge, J. Blanchard, M. Piatak, J.D. Lifson, J. FernándezRomero, T.M. Zydowsky, M. Robbiani, An intravaginal ring that releases three antiviral agents and a contraceptive blocks SHIV-RT infection, reduces HSV-2 shedding, and suppresses hormonal cycling in rhesus macaques, Drug Deliv. Transl. Res. 7 (2017) 840-858. doi:10.1007/s13346-017-0389-0.

[28] P.F. McKay, J.F.S. Mann, A. Pattani, V. Kett, Y. Aldon, D. King, R.K. Malcolm, R.J. Shattock, Intravaginal immunisation using a novel antigen-releasing ring device elicits robust vaccine antigen-specific systemic and mucosal humoral immune responses, J. Control. Release. 249 (2017) 74-83. doi:10.1016/j.jconrel.2017.01.018.

[29] M. Gunawardana, M.M. Baum, T.J. Smith, J.A. Moss, An intravaginal ring for the sustained delivery of antibodies, J. Pharm. Sci. 103 (2014) 3611-3620. doi:10.1002/jps.24154.

[30] G. Schmidt, S.-B. Andersson, Ö. Nordle, C.-J. Johansson, P.O. Gunnarsson, Release of 17-beta-oestradiol from a vaginal ring in postmenopausal women: pharmacokinetic evaluation, Gynecol. Obstet. Invest. 38 (1994) 253-260. doi:10.1159/000292492.

[31] U.S. Food and Drug Administration, Dissolution Methods Databse, (2018). https://www.accessdata.fda.gov/scripts/cder/dissolution/ (accessed June 1, 2018).

[32] K. Rainer, Method for dissolution testing of a pharmaceutical delivery device, US7357046, 2008.

[33] J.A.H. van Laarhoven, M.A.B. Kruft, H. Vromans, In vitro release properties of etonogestrel and ethinyl estradiol from a contraceptive vaginal ring, Int. J. Pharm. 232 (2002) 163-173. doi:10.1016/S0378-5173(01)00900-0.

[34] J.A.H. van Laarhoven, M.A.B. Kruft, H. Vromans, Effect of supersaturation and crystallization phenomena on the release properties of a controlled release device based on EVA copolymer, J. Control. Release. 82 (2002) 309-317. 
[35] J.A.H. van Laarhoven, Physical-chemical aspects of a coxial sustained release device based on poly-EVA (Dissertation), Utrecht University, 2005.

[36] A.D. Woolfson, G.R.E. Elliott, C.A. Gilligan, C.M. Passmore, Design of an intravaginal ring for the controlled delivery of $17 \mathrm{~b}$-estradiol as its 3-acetate ester, J. Control. Release. 61 (1999) 319-328.

[37] S.A. Matlin, A. Belenguer, P.E. Hall, Progesterone-releasing vaginal rings for use in postpartum contraception. I. In vitro release rates of progesterone from coreloaded rings, Contraception. 45 (1992) 329-341. doi:10.1016/00107824(92)90055-X.

953

954

[38] S.A. Matlin, A. Belenguer, In vitro release rate testing of progesterone from vaginal rings, S.T.P. Pharma. 3 (1987) 326-331.

[39] T. Jackanicz, H.B. Croxatto, L.G. Drexler, F. Zegers-Hochschild, Progesterone vaginal ring for treatment of infertility, US5869081A, 1999.

958

959

960

961

962

963

964

965

966

967

968

969

970

971

972

973

974

975

976

977

978

979

980

981

982

983

984

985

986

987

988

989

[40] A. Loxley, M. Mitchnick, H.G. Hernandez, C. Ronchi, Core sheath drug delivery devices, WO2013120888 A2, 2013.

[41] P. Spence, A. Nel, N. van Niekerk, T. Derrick, S. Wilder, B. Devlin, Post-use assay of vaginal rings (VRs) as a potential measure of clinical trial adherence, J. Pharm. Biomed. Anal. 125 (2016) 94-100. doi:10.1016/j.jpba.2016.03.023.

[42] A.R. Thurman, J.L. Schwartz, V. Brache, M.R. Clark, T. Mccormick, N. Chandra, M.A. Marzinke, F.Z. Stanczyk, S. Dezzutti, S.L. Hillier, B.C. Herold, R. Fichorova, S.N. Asin, C. Rollenhagen, D. Weiner, P. Kiser, G.F. Doncel, E. Virginia, U. States, Randomized, placebo controlled phase I trial of safety, pharmacokinetics, pharmacodynamics and acceptability of tenofovir and tenofovir plus levonorgestrel vaginal rings in women, PLoS One. 13 (2018) e0199778. doi:10.1371/journal. pone.0199778.

[43] T.J. Johnson, M.R. Clark, T.H. Albright, J.S. Nebeker, A.L. Tuitupou, J.T. Clark, J. Fabian, R.T. McCabe, N. Chandra, G.F. Doncel, D.R. Friend, P.F. Kiser, A 90day tenofovir reservoir intravaginal ring for mucosal HIV prophylaxis., Antimicrob. Agents Chemother. 56 (2012) 6272-83. doi:10.1128/AAC.01431-12.

[44] J.M. Smith, J.A. Moss, P. Srinivasan, I. Butkyavichene, M. Gunawardana, R. Fanter, C.S. Miller, D. Sanchez, F. Yang, S. Ellis, J. Zhang, M.A. Marzinke, C.W. Hendrix, A. Kapoor, M.M. Baum, Novel multipurpose pod-intravaginal ring for the prevention of HIV, HSV, and unintended pregnancy: Pharmacokinetic evaluation in a macaque model, PLoS One. 12 (2017) e0185946. doi:10.1371/journal.pone.0185946.

[45] P. Srinivasan, J.A. Moss, M. Gunawardana, S.A. Churchman, F. Yang, C.T. Dinh, J.M. Mitchell, J. Zhang, R. Fanter, C.S. Miller, I. Butkyavichene, J.M. McNicholl, T.J. Smith, M.M. Baum, J.M. Smith, Topical delivery of tenofovir disoproxil fumarate and emtricitabine from pod-intravaginal rings protects macaques from multiple SHIV exposures, PLoS One. 11 (2016) e0157061. doi:10.1371/journal.pone.0157061.

[46] J.A. Moss, I. Butkyavichene, S.A. Churchman, M. Gunawardana, R. Fanter, C.S. Miller, F. Yang, J.T. Easley, M.A. Marzinke, C.W. Hendrix, T.J. Smith, M.M. Baum, Combination pod-intravaginal ring delivers antiretroviral agents for HIV prophylaxis: pharmacokinetic evaluation in an ovine model, Antimicrob. Agents 

Chemother. 60 (2016) 3759-3766. doi:10.1128/AAC.00391-16.

991 [47] D.H. Owen, D.F. Katz, A vaginal fluid simulant., Contraception. 59 (1999) 91-5. doi:10.1016/S0010-7824(99)00010-4.

[48] M.R. Clark, T.J. Johnson, R.T. Mccabe, J.T. Clark, A. Tuitupou, H. Elgendy, D.R. Friend, P.F. Kiser, A hot-melt extruded intravaginal ring for the sustained delivery of the antiretroviral microbicide UC781, J. Pharm. Sci. 101 (2012) 576-587. doi:10.1002/jps.22781.

[49] A. Externbrink, K. Eggenreich, S. Eder, S. Mohr, K. Nickisch, S. Klein, Development and evaluation of accelerated drug release testing methods for a matrix-type intravaginal ring, Eur. J. Pharm. Biopharm. 110 (2017) 1-12. doi:10.1016/j.ejpb.2016.10.012.

[50] S.S. Iyer, W.H. Barr, H.T. Karnes, Profiling in vitro drug release from subcutaneous implants: a review of current status and potential implications on drug product

[51] T.J. Roseman, Release of steroids from a silicone polymer, J. Pharm. Sci. (1972). doi:10.1002/jps.2600610106.

1006

1007

1008

1009

1010

1011

1012

1013

[52] I.M. Helbling, J.C.D. Ibarra, J.A. Luna, The optimization of an intravaginal ring releasing progesterone using a mathematical model, Pharm. Res. 31 (2014) 795808. doi:10.1007/s11095-013-1201-6.

[53] A. Dokoumetzidis, P. Macheras, A century of dissolution research: from Noyes and Whitney to the biopharmaceutics classification system., Int. J. Pharm. 321 (2006) 1-11. doi:10.1016/j.ijpharm.2006.07.011.

[54] A.A. Noyes, W.R. Whitney, The rate of solution of solid substances in their own solutions, J. Am. Chem. Soc. 19 (1897) 930-934. doi:10.1021/ja02086a003.

1014

1015

1016

1017

1018

1019

1020

1021

1022

1023

1024

1025

1026

1027

1028

1029

1030

1031

1032

1033

1034

[55] K. Malcolm, D. Woolfson, J. Russell, P. Tallon, L. McAuley, D. Craig, Influence of silicone elastomer solubility and diffusivity on the in vitro release of drugs from intravaginal rings, J. Control. Release. 90 (2003) 217-225. doi:10.1016/S01683659(03)00178-0.

[56] K. Malcolm, D. Woolfson, J. Russell, C. Andrews, In vitro release of nonoxynol-9 from silicone matrix intravaginal rings., J. Control. Release. 91 (2003) 355-64. http://www.ncbi.nlm.nih.gov/pubmed/12932713.

[57] F. Acartürk, N. Altug, In-vitro and in-vivo evaluation of a matrix-controlled bromocriptine mesilate-releasing vaginal ring, J. Pharm. Pharmacol. 53 (2003) 1721-1726. doi:10.1211/0022357011778124.

[58] Y. Zhang, C.-X. Li, M.-Y. Ning, X.-Y. Duan, Y. Liu, Preparation and evaluation of intravaginal ring containing drospirenone., Adv. Pharmacol. Sci. 2013 (2013) 192408. doi:10.1155/2013/192408.

[59] Y.W. Chien, S.E. Mares, J. Berg, S. Huber, H.J. Lambert, K.F. King, Controlled drug release from polymeric delivery devices. III: In vitro-in vivo correlation for intravaginal release of ethynodiol diacetate from silicone devices in rabbits., J. Pharm. Sci. 64 (1975) 1776-81. doi:10.1002/jps.2600641108.

[60] Y.W. Chien, H.J. Lambert, Controlled drug release from polymeric delivery devices II: Differentiation between partition-controlled and matrix-controlled drug release mechanisms, J. Pharm. Sci. 63 (1974) 515-519. doi:10.1002/jps.2600630405.

[61] Y.W. Chien, H.J. Lambert, T.K. Lin, Solution-solubility dependency of controlled 
release of drug from polymer matrix: mathematical analysis, J. Pharm. Sci. 64 (1975) 1643-1647. doi:10.1002/jps.2600641011.

[62] D.J. Murphy, D. Desjardins, P. Boyd, N. Dereuddre-bosquet, L. Stimmer, A. Caldwell, R. Le, C. Kelly, J. Van Roey, R.K. Malcolm, Impact of ring size and drug loading on the pharmacokinetics of a combination dapivirine-darunavir vaginal ring in cynomolgus macaques, Int. J. Pharm. 550 (2018) 300-308. doi:10.1016/j.ijpharm.2018.08.051.

[63] C. McConville, I. Major, D.R. Friend, M.R. Clark, R.K. Malcolm, Development of a UC781 releasing polyethylene vinyl acetate vaginal ring, Drug Deliv. Transl. Res. 2 (2012) 489-497. doi:10.1007/s13346-012-0101-3.

[64] P. Boyd, S.M. Fetherston, C.F. McCoy, I. Major, D.J. Murphy, S. Kumar, J. Holt, A. Brimer, W. Blanda, B. Devlin, R.K. Malcolm, Matrix and reservoir-type multipurpose vaginal rings for controlled release of dapivirine and levonorgestrel, Int. J. Pharm. 511 (2016) 619-629. doi:10.1016/j.ijpharm.2016.07.051.

[65] D.J. Murphy, P. Boyd, C.F. McCoy, S. Kumar, J.D.S. Holt, W. Blanda, A.N. Brimer, R.K. Malcolm, Controlling levonorgestrel binding and release in a multipurpose prevention technology vaginal ring device, J. Control. Release. 226 (2016) 138-147. doi:10.1016/j.jconrel.2016.02.020.

[66] D.J. Murphy, D. Desjardins, N. Dereuddre-Bosquet, P. Brochard, L. Perrot, A. Pruvost, R. Le Grand, O. Lagatie, L. Vanhooren, M. Feyaerts, J. van Roey, R.K. Malcolm, Pre-clinical development of a combination microbicide vaginal ring containing dapivirine and darunavir, J. Antimicrob. Chemother. 69 (2014) 24772488. doi:10.1093/jac/dku160.

[67] S.M. Fetherston, L. Geer, R.S. Veazey, L. Goldman, D.J. Murphy, T.J. Ketas, P.J. Klasse, S. Blois, P. La Colla, J.P. Moore, R.K. Malcolm, Partial protection against multiple RT-SHIV162P3 vaginal challenge of rhesus macaques by a silicone elastomer vaginal ring releasing the NNRTI MC1220, J. Antimicrob. Chemother. 68 (2013) 394-403. doi:10.1093/jac/dks415.

[68] R.K. Malcolm, A.D. Woolfson, C.F. Toner, R.J. Morrow, S.D. McCullagh, Longterm, controlled release of the HIV microbicide TMC120 from silicone elastomer vaginal rings, J. Antimicrob. Chemother. 56 (2005) 954-956. doi:10.1093/jac/dki326.

[69] K. Tietz, S. Klein, Simulated genital tract fluids and their applicability in drug release/dissolution testing of vaginal dosage forms, Dissolution Technol. 25 (2018) 40-51. doi:10.14227/DT250318P40.

[70] K.S. Moghissi, Postcoital test: physiologic basis, technique, and interpretation., Fertil. Steril. 27 (1976) 117-29. http://www.ncbi.nlm.nih.gov/pubmed/1248657.

[71] A. Makler, R. David, Z. Blumenfeld, O.S. Better, Factors affecting sperm motility. VII. Sperm viability as affected by change of $\mathrm{pH}$ and osmolarity of semen and urine specimens., $\quad$ Fertil. $\quad$ Steril. $36 \quad$ (1981) 507-11. http://www.ncbi.nlm.nih.gov/pubmed/7286273.

[72] M. Jug, A. Hafner, J. Lovrić, M.L. Kregar, I. Pepić, Ž. Vanić, B. Cetina-Čižmek, J. Filipović-Grčić, An overview of in vitro dissolution/release methods for novel mucosal drug delivery systems, J. Pharm. Biomed. Anal. 147 (2018) 350-366. doi:10.1016/j.jpba.2017.06.072.

[73] J.W. McBride, N. Dias, D. Cameron, R.E. Offord, O. Hartley, P. Boyd, V.L. Kett, 
R.K. Malcolm, Pharmacokinetics of the protein microbicide 5P12-RANTES in sheep following single-dose vaginal gel administration, Antimicrob. Agents Chemother. 61 (2017) AAC.00965-17. doi:10.1128/AAC.00965-17.

[74] C. Huang, S.J. Soenen, E. van Gulck, G. Vanham, J. Rejman, S. Van Calenbergh, C. Vervaet, T. Coenye, H. Verstraelen, M. Temmerman, J. Demeester, S.C. De Smedt, Electrospun cellulose acetate phthalate fibers for semen induced anti-HIV vaginal drug delivery, Biomaterials. $33 \quad$ (2012) 962-969. doi:10.1016/j.biomaterials.2011.10.004.

[75] J.A. Moss, A.M. Malone, T.J. Smith, S. Kennedy, E. Kopin, C. Nguyen, J. Gilman, I. Butkyavichene, K.L. Vincent, M. Motamedi, D.R. Friend, M.R. Clark, M.M. Baum, Simultaneous delivery of tenofovir and acyclovir via an intravaginal ring., Antimicrob. Agents Chemother. 56 (2012) 875-82. doi:10.1128/AAC.05662-11.

[76] N.H. Asvadi, N.T.T. Dang, N. Davis-Poynter, A.G.A. Coombes, Evaluation of microporous polycaprolactone matrices for controlled delivery of antiviral microbicides to the female genital tract, J. Mater. Sci. Mater. Med. 24 (2013) 27192727. doi:10.1007/s10856-013-5010-6.

[77] R. Cazorla-luna, F. Notario-pérez, A. Martín-illana, R. Ruiz-caro, Chitosan-based mucoadhesive vaginal tablets for controlled release of the anti-HIV drug tenofovir, Pharmaceutics. 11 (2019) 1-19. doi:10.3390/pharmaceutics11010020.

[78] C.J. Forbes, D. Lowry, L. Geer, R.S. Veazey, R.J. Shattock, P.J. Klasse, M. Mitchnick, L. Goldman, L. a Doyle, B.C.O. Muldoon, a D. Woolfson, J.P. Moore, R.K. Malcolm, Non-aqueous silicone elastomer gels as a vaginal microbicide delivery system for the HIV-1 entry inhibitor maraviroc, J. Control. Release. 156 (2011) 161-169. doi:10.1016/j.jconrel.2011.08.006.

[79] C.J. Forbes, C.F. Mccoy, D.J. Murphy, A. David Woolfson, J.P. Moore, A. Evans, R.J. Shattock, R. Karl Malcolm, Modified silicone elastomer vaginal gels for sustained release of antiretroviral HIV microbicides, J. Pharm. Sci. 103 (2014) 1422-1432. doi:10.1002/jps.23913.

[80] R.K. Malcolm, R.S. Veazey, L. Geer, D. Lowry, S.M. Fetherston, D.J. Murphy, P. Boyd, I. Major, R.J. Shattock, P.J. Klasse, L.A. Doyle, K.K. Rasmussen, L. Goldman, T.J. Ketas, J.P. Moore, Sustained release of the CCR5 inhibitors CMPD167 and maraviroc from vaginal rings in rhesus macaques, Antimicrob. Agents Chemother. 56 (2012) 2251-2258. doi:10.1128/AAC.05810-11.

[81] M.R.C. Marques, R. Loebenberg, M. Almukainzi, Simulated biological fluids with possible application in dissolution testing, Dissolution Technol. 18 (2011) 15-28. doi:10.14227/DT180311P15.

[82] F. Mashingaidze, Y.E. Choonara, P. Kumar, L.C. du Toit, V. Maharaj, E. Buchmann, V. Pillay, Submicron matrices embedded in a polymeric caplet for extended intravaginal delivery of zidovudine, AAPS J. 19 (2017) 1745-1759. doi:10.1208/s 12248-017-0130-4.

[83] C. McConville, I. Major, D.R. Friend, M.R. Clark, A.D. Woolfson, R.K. Malcolm, Development of polylactide and polyethylene vinyl acetate blends for the manufacture of vaginal rings, J. Biomed. Mater. Res. Part B Appl. Biomater. 100B (2012) 891-895. doi:10.1002/jbm.b.31919.

[84] D.J. Murphy, K. Amssoms, G. Pille, A. Clarke, M. O’Hara, J. van Roey, R.K. Malcolm, Sustained release of the candidate antiretroviral peptides T-1249 and 
[85] M. Pathak, M. Turner, C. Palmer, A.G. Coombes, Evaluation of polycaprolactone matrices for the intravaginal delivery of metronidazole in the treatment of bacterial 234-242. doi:10.1007/s13346-015-0273-8. vaginosis, J. Biomater. Appl. 29 (2014) 354-363. doi:10.1177/0885328214528256.

[86] M. Pathak, A.G.A. Coombes, M.S. Turner, C. Palmer, D. Wang, K.J. Steadman, Investigation of Polycaprolactone Matrices for Intravaginal Delivery of Doxycycline, J. Pharm. Sci. 104 (2015) 4217-4222. doi:10.1002/jps.24652.

[87] M. Pathak, A.G.A. Coombes, B.M. Ryu, P.J. Cabot, M.S. Turner, C. Palmer, D. Wang, K.J. Steadman, Sustained simultaneous delivery of metronidazole and doxycycline from polycaprolactone matrices designed for intravaginal treatment of pelvic inflammatory disease, J. Pharm. Sci. 107 (2018) 863-869. doi:10.1016/j.xphs.2017.09.033.

[88] J. das Neves, J. Michiels, K.K. Ariën, G. Vanham, M. Amiji, M.F. Bahia, B. Sarmento, Polymeric nanoparticles affect the intracellular delivery, antiretroviral activity and cytotoxicity of the microbicide drug candidate dapivirine, Pharm. Res. 29 (2012) 1468-1484. doi:10.1007/s11095-011-0622-3.

[89] N.T.T. Dang, H. Sivakumaran, D. Harrich, A.G.A. Coombes, An evaluation of polycaprolactone matrices for vaginal delivery of the antiviral, tenofovir, in preventing heterosexual transmission of HIV, J. Pharm. Sci. 102 (2013) 3725-3735. doi:10.1002/jps.23684.

[90] D. Pliszczak, S. Bourgeois, C. Bordes, J.P. Valour, M.A. Mazoyer, A.M. Orecchioni, E. Nakache, P. Lantéri, Improvement of an encapsulation process for the preparation of pro- and prebiotics-loaded bioadhesive microparticles by using experimental design, Eur. J. Pharm. Sci. 44 (2011) 83-92. doi:10.1016/j.ejps.2011.06.011.

[91] M. Aravantinou, R. Singer, N. Derby, G. Calenda, P. Mawson, C.J. Abraham, R. Menon, S. Seidor, D. Goldman, J. Kenney, G. Villegas, A. Gettie, J. Blanchard, J.D. Lifson, M. Piatak, J.A. Fernández-Romero, T.M. Zydowsky, N. Teleshova, M. Robbiani, The nonnucleoside reverse transcription inhibitor MIV-160 delivered from an intravaginal ring, but not from a carrageenan gel, protects against simian/human immunodeficiency virus-RT infection, AIDS Res. Hum. Retroviruses. 28 (2012) 1467-1475. doi:10.1089/aid.2012.0080.

[92] S.R. Ugaonkar, J.T. Clark, L.B. English, T.J. Johnson, K.W. Buckheit, R.J. Bahde, D.H. Appella, R.W. Buckheit, P.F. Kiser, An intravaginal ring for the simultaneous delivery of an HIV-1 maturation inhibitor and reverse-transcriptase inhibitor forprophylaxis of HIV transmission, J. Pharm. Sci. 104 (2015) 3426-3439. doi:10.1002/jps.24551.

[93] C. McConville, J.M. Smith, C.F. McCoy, P. Srinivasan, J. Mitchell, A. Holder, R.A. Otten, S. Butera, G.F. Doncel, D.R. Friend, R.K. Malcolm, Lack of in vitro-in vivo correlation for a UC781-releasing vaginal ring in macaques, Drug Deliv. Transl. Res. 5 (2015) 27-37. doi:10.1007/s13346-015-0216-4.

[94] H.A. Nash, V. Brache, F. Alvarez-Sanchez, T.M. Jackanicz, T.M. Harmon, Estradiol delivery by vaginal rings: Potential for hormone replacement therapy, Maturitas. (1997). doi:10.1016/S0378-5122(96)01072-9.

[95] S.M. Fetherston, P. Boyd, C.F. McCoy, M.C. McBride, K.-L. Edwards, S. Ampofo, 
R.K. Malcolm, A silicone elastomer vaginal ring for HIV prevention containing two microbicides with different mechanisms of action, Eur. J. Pharm. Sci. 48 (2013) 406-415. doi:10.1016/j.ejps.2012.12.002.

[96] B. Devlin, J. Nuttall, S. Wilder, C. Woodsong, Z. Rosenberg, Development of dapivirine vaginal ring for HIV prevention, Antiviral Res. 100 (2013) S3-S8. doi:10.1016/j.antiviral.2013.09.025.

[97] A.D. Woolfson, M.L. Umrethia, V.L. Kett, R.K. Malcolm, Freeze-dried, mucoadhesive system for vaginal delivery of the HIV microbicide, dapivirine: Optimisation by an artificial neural network, Int. J. Pharm. 388 (2010) 136-143. doi:10.1016/j.ijpharm.2009.12.042.

[98] G. Dezarnaulds, I.S. Fraser, Vaginal ring delivery of hormone replacement therapy - a review, Expert Opin. Pharmacother. 4 (2002) 201-212. doi:10.1517/14656566.4.2.201.

[99] C.A.F. Guazzelli, M. Barbieri, C.S. Vieira, M.R. Torloni, New developments in vaginal rings for contraception, Curr. Obstet. Gynecol. Rep. 3 (2014) 143-149. doi:10.1007/s13669-014-0080-0.

[100] V. Brache, L.J. Payán, A. Faundes, Current status of contraceptive vaginal rings, Contraception. 87 (2013) 264-272. doi:10.1016/j.contraception.2012.08.037.

[101] W. De Graff, J.S. Groen, M.A. Kruft, J.A.H. Van Laarhoven, H. Vromans, Drug delivery system based on polyethylene vinylacetate copolymers, US patent 8808744B2, 2009.

[102] R. Kraft, Method for dissolution testing off a pharmaceutical delivery device, US7357046, 2008.

[103] A. Shareef, M.J. Angove, J.D. Wells, B.B. Johnson, Aqueous solubilities of estrone, 17 $\beta$-estradiol, 17 $\alpha$-ethynylestradiol, and bisphenol A, J. Chem. Eng. Data. 51 (2006) 879-881. doi:10.1021/je050318c.

[104] A. Externbrink, M.R. Clark, D.R. Friend, S. Klein, Investigating the feasibility of temperature-controlled accelerated drug release testing for an intravaginal ring, Eur. J. Pharm. Biopharm. 85 (2013) 966-973. doi:10.1016/j.ejpb.2013.06.004.

[105] J.M. Baeten, T. Palanee-Phillips, E.R. Brown, K. Schwartz, L.E. Soto-Torres, V. Govender, N.M. Mgodi, F. Matovu Kiweewa, G. Nair, F. Mhlanga, S. Siva, L.-G.G. Bekker, N. Jeenarain, Z. Gaffoor, F. Martinson, B. Makanani, A. Pather, L. Naidoo, M. Husnik, B.A. Richardson, U.M. Parikh, J.W. Mellors, M.A. Marzinke, C.W. Hendrix, A. van der Straten, G. Ramjee, Z.M. Chirenje, C. Nakabiito, T.E. Taha, J. Jones, A. Mayo, R. Scheckter, J. Berthiaume, E. Livant, C. Jacobson, P. Ndase, R. White, K. Patterson, D. Germuga, B. Galaska, K. Bunge, D. Singh, D.W. Szydlo, E.T. Montgomery, B.S. Mensch, K. Torjesen, C.I. Grossman, N. Chakhtoura, A. Nel, Z. Rosenberg, I. McGowan, S. Hillier, F.M. Kiweewa, G. Nair, F. Mhlanga, S. Siva, L.-G.G. Bekker, N. Jeenarain, Z. Gaffoor, F. Martinson, B. Makanani, A. Pather, L. Naidoo, M. Husnik, B.A. Richardson, U.M. Parikh, J.W. Mellors, M.A. Marzinke, C.W. Hendrix, A. van der Straten, G. Ramjee, Z.M. Chirenje, C. Nakabiito, T.E. Taha, J. Jones, A. Mayo, R. Scheckter, J. Berthiaume, E. Livant, C. Jacobson, P. Ndase, R. White, K. Patterson, D. Germuga, B. Galaska, K. Bunge, D. Singh, D.W. Szydlo, E.T. Montgomery, B.S. Mensch, K. Torjesen, C.I. Grossman, N. Chakhtoura, A. Nel, Z. Rosenberg, I. McGowan, S. Hillier, Use of a vaginal ring containing dapivirine for HIV-1 prevention in women, N. Engl. J. Med. 375 (2016) 
[106] A. Nel, N. van Niekerk, S. Kapiga, L.-G. Bekker, C. Gama, K. Gill, A. Kamali, P. Kotze, C. Louw, Z. Mabude, N. Miti, S. Kusemererwa, H. Tempelman, H. Carstens, B. Devlin, M. Isaacs, M. Malherbe, W. Mans, J. Nuttall, M. Russell, S. Ntshele, M. Smit, L. Solai, P. Spence, J. Steytler, K. Windle, M. Borremans, S. Resseler, J. Van Roey, W. Parys, T. Vangeneugden, B. Van Baelen, Z. Rosenberg, Safety and efficacy of a dapivirine vaginal ring for HIV prevention in women, N. Engl. J. Med. 375 (2016) 2133-2143. doi:10.1056/NEJMoa1602046.

[107] A.D. Woolfson, R.K. Malcolm, R.J. Morrow, C.F. Toner, S.D. McCullagh, Intravaginal ring delivery of the reverse transcriptase inhibitor TMC 120 as an HIV microbicide, Int. J. Pharm. 325 (2006) 82-89. doi:10.1016/j.ijpharm.2006.06.026.

[108] J. Siepmann, F. Siepmann, Modeling of diffusion controlled drug delivery, J. Control. Release. 161 (2012) 351-362. doi:10.1016/j.jconrel.2011.10.006.

[109] Y. Zhou, X.Y. Wu, Theoretical analyses of dispersed-drug release from planar matrices with a boundary layer in a finite medium, J. Control. Release. 84 (2002) 1-13. doi:10.1016/S0168-3659(02)00263-8.

[110] G. Frenning, Modelling drug release from inert matrix systems: from movingboundary to continuous-field descriptions., Int. J. Pharm. 418 (2011) 88-99. doi:10.1016/j.ijpharm.2010.11.030.

[111] Y.W. Chien, H.J. Lambert, D.E. Grant, Controlled drug release from polymeric devices I: Technique for rapid in vitro release studies, J. Pharm. Sci. 63 (1974) $365-$ 369. doi:10.1002/jps.2600630311.

[112] F.G. Burton, W.E. Skiens, N.R. Gordon, J.T. Veal, D.R. Kalkwarf, G.W. Duncan, Fabrication and testing of vaginal contraceptive devices designed for release of prespecified dose levels of steroids, Contraception. 17 (1978) 221-230. doi:10.1016/0010-7824(78)90013-6.

[113] T. Higuchi, Rate of release of medicaments from ointment bases containing drugs in suspension, J. Pharm. Sci. 50 (1961) 874-875. doi:10.1002/jps.2600501018.

[114] J. Siepmann, N.A. Peppas, Higuchi equation: derivation, applications, use and misuse., Int. J. Pharm. 418 (2011) 6-12. doi:10.1016/j.ijpharm.2011.03.051.

[115] M. Grassi, G. Grassi, Mathematical modelling and controlled drug delivery: matrix systems., Curr. Drug Deliv. 2 (2005) 97-116. http://www.ncbi.nlm.nih.gov/pubmed/16305412.

[116] J. Fu, X. Yu, Y. Jin, 3D printing of vaginal rings with personalized shapes for controlled release of progesterone, Int. J. Pharm. 539 (2018) 75-82. doi:10.1016/j.ijpharm.2018.01.036.

[117] K.M. Gupta, S.M. Pearce, A.E. Poursaid, H.A. Aliyar, P.A. Tresco, M.A. Mitchnik, P.F. Kiser, Polyurethane intravaginal ring for controlled delivery of dapivirine, a nonnucleoside reverse transcriptase inhibitor of HIV-1, J. Pharm. Sci. 97 (2008) 4228-4239. doi:10.1002/jps.21331.

[118] I.M. Helbling, J. a Luna, M.I. Cabrera, Mathematical modeling of drug delivery from torus-shaped single-layer devices, J. Control. Release. 149 (2011) 258-263. doi:10.1016/j.jconrel.2010.10.018.

[119] C. McConville, J.M. Smith, C.F. McCoy, P. Srinivasan, J. Mitchell, A. Holder, R. a Otten, S. Butera, G.F. Doncel, D.R. Friend, R.K. Malcolm, Lack of in vitro-in 

vivo correlation for a UC781-releasing vaginal ring in macaques, Drug Deliv. Transl. Res. 5 (2015) 27-37. doi:10.1007/s13346-015-0216-4.

[120] R. Nave, T. Jalkanen, C. Talling, M. Kaneko, S. Matsuki, J. Höchel, The Effect of Drug Content Reduction on the In Vitro and In Vivo Properties of LevonorgestrelReleasing Intravaginal Rings, J. Pharm. Sci. 107 (2018) 1020-1027. doi:10.1016/j.xphs.2017.11.009.

[121] A. Pattani, D. Lowry, R.M. Curran, S. McGrath, V.L. Kett, G.P. Andrews, R.K. Malcolm, Characterisation of protein stability in rod-insert vaginal rings, Int. J. Pharm. 430 (2012) 89-97. doi:10.1016/j.ijpharm.2012.03.036.

1273

1274

1275

[122] X. Duan, M. Ning, Development and in vitro/in vivo evaluation of a silastic intravaginal ring for mifepristone delivery, Indian J. Pharm. Sci. 77 (2015) 335. doi:10.4103/0250-474X.159671.

[123] T. Higuchi, Mechanism of sustained-action medication. Theoretical analysis of rate of release of solid drugs dispersed in solid matrices, J. Pharm. Sci. 52 (1963) 11451149. doi:10.1002/jps.2600521210.

[124] W.I. Higuchi, Diffusional models useful in biopharmaceutics. Drug release rate processes, J. Pharm. Sci. 56 (1967) 315-324. doi:10.1002/jps.2600560302.

[125] N.A. Peppas, Analysis of Fickian and non-Fickian drug release from polymers., Pharm. Acta Helv. 60 (1985) 110-1. http://www.ncbi.nlm.nih.gov/pubmed/4011621.

[126] J. Crank, The Mathematics of Diffusion, 2nd Editio, Oxford University Press, London, 1975.

[127] R.W. Baker, H.K. Lonsdale, Controlled Release: Mechanisms and Rates, in: A.C. Tanquary, R.E.C. Lacey (Eds.), Control. Release Biol. Act. Agents, Plenum Press, New York, 1974: pp. 15-71.

[128] A.D. Woolfson, R.K. Malcolm, R.J. Gallagher, Design of a silicone reservoir intravaginal ring for the delivery of oxybutynin, J. Control. Release. 91 (2003) 465476. doi:10.1016/S0168-3659(03)00277-3.

[129] C. Schneider, R. Langer, D. Loveday, D. Hair, Applications of ethylene vinyl acetate copolymers (EVA) in drug delivery systems, J. Control. Release. 262 (2017) 284-295. doi:10.1016/j.jconrel.2017.08.004.

[130] W. De Graff, A. Szegedi, Delivery system for risperidone, US2010/0203104A1, 2010.

[131] W. De Graff, A. Szegedi, Delivery system for a non-steroidal non-ionized hydrophilic drug, US2010/0104619A1, 2010.

[132] B.S. Zolnik, P.E. Leary, D.J. Burgess, Elevated temperature accelerated release testing of PLGA microspheres, J. Control. Release. 112 (2006) 293-300. doi:10.1016/j.jconrel.2006.02.015.

[133] B.S. Zolnik, D.J. Burgess, Effect of acidic pH on PLGA microsphere degradation and release, J. Control. Release. $122 \quad$ (2007) 338-344. doi:10.1016/j.jconrel.2007.05.034.

[134] S.S. Iyer, W.H. Barr, H.T. Karnes, A “biorelevant” approach to accelerated in vitro drug release testing of a biodegradable, naltrexone implant, Int. J. Pharm. 340 (2007) 119-125. doi:10.1016/j.ijpharm.2007.03.033. 
[135] M. Kamberi, S. Nayak, K. Myo-Min, T.P. Carter, L. Hancock, D. Feder, A novel accelerated in vitro release method for biodegradable coating of drug eluting stents: Insight to the drug release mechanisms, Eur. J. Pharm. Sci. 37 (2009) 217-222. doi:10.1016/j.ejps.2009.02.009.

[136] J. Emami, In vitro - in vivo correlation: from theory to applications., J. Pharm. Pharm. Sci. 9 (2006) 169-89. http://www.ncbi.nlm.nih.gov/pubmed/16959187.

[137] P. Marroum, Role of in vitro-in vivo correlations in drug development, Dissolution Technol. 22 (2015) 50-56. doi:10.14227/DT220215P50.

[138] J.-M. Cardot, E. Beyssac, M. Alric, In vitro-in vivo vorrelation: importance of dissolution in IVIVC, Dissolution Technol. 14 (2007) 15-19. doi:10.14227/DT140107P15.

[139] E.S. Kostewicz, B. Abrahamsson, M. Brewster, J. Brouwers, J. Butler, S. Carlert, P.A. Dickinson, J. Dressman, R. Holm, S. Klein, J. Mann, M. Mcallister, M. Minekus, U. Muenster, A. Müllertz, M. Verwei, M. Vertzoni, W. Weitschies, P. Augustijns, In vitro models for the prediction of in vivo performance of oral dosage forms, Eur. J. Pharm. Sci. 57 (2014) 342-366. doi:10.1016/j.ejps.2013.08.024.

[140] U.S. Department of Health and Human Services Food and Drug Administration Center for Drug Evaluation and Research (CDER), Guidance for Industry: Extended Release Oral Dosage Forms: Development, Evaluation, and Application of In Vitro/In Vivo Correlations, 1997.

[141] USP 41-NF 36, In vitro and In vivo Evaluations of Dosage Forms, in: United States Pharmacop. Natl. Formul., USP 41-NF, Mack Publishing Co., Easton, PA., 2018.

[142] M.A. Nguyen, T. Flanagan, M. Brewster, F. Kesisoglou, S. Beato, J. Biewenga, J. Crison, R. Holm, R. Li, E. Mannaert, M. McAllister, M. Mueller-Zsigmondy, U. Muenster, K. Ojala, S. Page, A. Parr, S. Rossenu, P. Timmins, A. Van Peer, A. Vermeulen, P. Langguth, A survey on IVIVC/IVIVR development in the pharmaceutical industry - Past experience and current perspectives, Eur. J. Pharm. Sci. 102 (2017) 1-13. doi:10.1016/j.ejps.2017.02.029.

[143] A. Mendyk, P.K. Tuszyński, S. Polak, R. Jachowicz, Generalized in vitro-in vivo relationship (IVIVR) model based on artificial neural networks., Drug Des. Devel. Ther. 7 (2013) 223-32. doi:10.2147/DDDT.S41401.

[144] D.T. Mauger, V.M. Chinchilli, In vitro-in vivo relationships for oral extendedrelease drug products, in: J. Biopharm. Stat., 1997. doi:10.1080/10543409708835207.

[145] S. Suarez-Sharp, M. Cohen, F. Kesisoglou, A. Abend, P. Marroum, P. Delvadia, E. Kotzagiorgis, M. Li, A. Nordmark, N. Bandi, E. Sjögren, A. Babiskin, T. Heimbach, S. Kijima, H. Mandula, K. Raines, P. Seo, X. Zhang, Applications of Clinically Relevant Dissolution Testing: Workshop Summary Report, AAPS J. 20 (2018) 93. doi:10.1208/s12248-018-0252-3.

[146] S. Suarez-Sharp, M. Li, J. Duan, H. Shah, P. Seo, Regulatory Experience with In Vivo In Vitro Correlations (IVIVC) in New Drug Applications, AAPS J. 18 (2016) 1379-1390. doi:10.1208/s12248-016-9966-2.

[147] J. Shen, D.J. Burgess, In vitro-in vivo correlation for complex non-oral drug products: Where do we stand?, J. Control. Release. 219 (2015) 644-651. doi:10.1016/j.jconrel.2015.09.052. 
[148] Y. Yang, P. Manda, N. Pavurala, M.A. Khan, Y.S.R. Krishnaiah, Development and validation of in vitro-in vivo correlation (IVIVC) for estradiol transdermal drug delivery systems, J. Control. Release. 210 (2015) 58-66. doi:10.1016/j.jconrel.2015.05.263.

[149] Y. Qiu, J.Z. Duan, In Vitro/In Vivo Correlations: Fundamentals, Development Considerations, and Applications, in: Y. Qiu, Y. Chen, G.G.Z. Zhang, L. Yu, R. V. Mantri (Eds.), Dev. Solid Oral Dos. Forms, Pharm. Theory Pract., 2nd Editio, 2017: pp. 415-452.

[150] A. Nel, S. Smythe, K. Young, K. Malcolm, C. McCoy, Z. Rosenberg, J. Romano, Safety and pharmacokinetics of dapivirine delivery from matrix and reservoir intravaginal rings to HIV-negative women, JAIDS J. Acquir. Immune Defic. Syndr. 51 (2009) 416-423. doi:10.1097/QAI.0b013e3181acb536.

[151] B.A. Chen, L. Panther, M.A. Marzinke, C.W. Hendrix, C.J. Hoesley, A. van der Straten, M.J. Husnik, L. Soto-Torres, A. Nel, S. Johnson, N. Richardson-Harman, L.K. Rabe, C.S. Dezzutti, Phase 1 safety, pharmacokinetics, and pharmacodynamics of dapivirine and maraviroc vaginal rings: a double-blind randomized trial, J. Acquir. Immune Defic. Syndr. 70 (2015) 242-9. doi:10.1097/QAI.0000000000000702.

[152] A. Nel, W. Haazen, J. Nuttall, J. Romano, Z. Rosenberg, N. van Niekerk, A safety and pharmacokinetic trial assessing delivery of dapivirine from a vaginal ring in healthy women, AIDS. 28 (2014) 1479-1487. doi:10.1097/QAD.0000000000000280.

[153] A. Nel, W. Haazen, J.P. Nuttall, J.W. Romano, P.M. Mesquita, B.C. Herold, Z.F. Rosenberg, N. van Niekerk, Pharmacokinetics and safety assessment of anti-HIV dapivirine vaginal microbicide rings with multiple sosing, J. AIDS Clin. Res. 5 (2014) 1000355. doi:10.4172/2155-6113.1000355.

[154] C.J. Timmer, T.M. Mulders, Pharmacokinetics of etonogestrel and ethinylestradiol released from a combined contraceptive vaginal ring., Clin. Pharmacokinet. 39 (2000) 233-42. doi:10.2165/00003088-200039030-00005.

[155] P.J. Marroum, In vitro-in vivo correlation: a regulatory perspective with case studies, in: C.D. Murthy, G. Sunkara, D. Young (Eds.), Pharm. Prod. Dev. Vitr. Vivo Correl., CRC Press, New York, 2007.

[156] W. Liu, X. Song, S. Zhao, M. He, H. Wang, Z. Chen, W. Xiang, G. Yi, S. Qi, Y. Liu, Antitumor activity and mechanism of a reverse transcriptase inhibitor, dapivirine, in glioblastoma, J. Cancer. 9 (2018) 117-128. doi:10.7150/jca.21965.

[157] C.J. Timmer, D. Apter, G. Voortman, Pharmacokinetics of 3-keto-desogestrel and ethinylestradiol released from different types of contraceptive vaginal rings, Contraception. 42 (1990) 629-642. doi:10.1016/0010-7824(90)90004-F.

[158] B.-M. Landgren, P.E. Hall, S.Z. Cekan, Progesterone-releasing vaginal rings for use in postpartum contraception. II. Pharmacokinetic profiles in women, Contraception. 45 (1992) 343-349. doi:10.1016/0010-7824(92)90056-Y.

[159] B.-M. Landgren, B. Jonsson, S.Z. Cekan, The effect of small doses of progesterone released from two types of vaginal rings on ovarian activity and bleeding patterns during the first postpartum year, Contraception. 51 (1995) 255-260. doi:10.1016/0010-7824(95)00042-9.

[160] M.R. Clark, P.F. Kiser, A. Loxley, C. McConville, R.K. Malcolm, D.R. Friend, 
Pharmacokinetics of UC781-loaded intravaginal ring segments in rabbits: A comparison of polymer matrices, Drug Deliv. Transl. Res. 1 (2011) 238-246. doi:10.1007/s 13346-011-0032-4.

[161] P.F. Kiser, A. Mahalingam, J. Fabian, E. Smith, F.R. Damian, J.J. Peters, D.F. Katz, H. Elgendy, M.R. Clark, D.R. Friend, Design of tenofovir-UC781 combination microbicide vaginal gels., J. Pharm. Sci. 101 (2012) 1852-64. doi:10.1002/jps.23089.

[162] A. Zussman, L. Lara, H.H. Lara, Z. Bentwich, G. Borkow, Blocking of cell-free and cell-associated HIV-1 transmission through human cervix organ culture with UC781., AIDS. 17 (2003) 653-61. doi:10.1097/01.aids.0000050826.06065.5f.

[163] T.J. Johnson, P. Srinivasan, T.H. Albright, K. Watson-Buckheit, L. Rabe, A. Martin, C.-P. Pau, R.M. Hendry, R. Otten, J. McNicholl, R. Buckheit, J. Smith, P.F. Kiser, Safe and sustained vaginal delivery of pyrimidinedione HIV-1 inhibitors from polyurethane intravaginal rings., Antimicrob. Agents Chemother. 56 (2012) 1291-9. doi:10.1128/AAC.05721-11.

[164] D.J. Murphy, C.F. McCoy, M. Plagianos, S. Ramarao, H. Clark, P. Boyd, B. Variano, R.K. Malcolm, Post-use ring weight and residual drug content as potential objective measures of user adherence to a contraceptive progesterone vaginal ring, Contraception. in press (2019).

[165] K. Kay, D.K. Shah, L. Rohan, R. Bies, Physiologically-based pharmacokinetic model of vaginally administered dapivirine ring and film formulations, Br. J. Clin. Pharmacol. 84 (2018) 1950-1969. doi:10.1111/bcp.13625. 


\section{Table and figure captions}

1423 Fig. 1. Plot of $\log$ partition coefficient (log P; experimental or calculated values; protein

1424 molecules arbitrarily assigned a value of 1 , due to lack of data) vs. molecular weight for

1425 drug molecules in marketed vaginal rings or having previously been considered for

1426 formulation in vaginal rings. Plot symbols inside the dashed box include estradiol,

1427 ethinyl estradiol, etonogestrel, estradiol-3- acetate, dapivirine, progesterone,

1428 levonorgestrel, maraviroc, MIV-150, oxybutynin, segesterone acetate (Nestorone ${ }^{\circledR}$ ),

1429 norethindrone acetate, ulipristal acetate, medroxyprogesterone acetate, UC781, danazol,

1430 MC1220, CMPD-167, drosperinone, nomegestol acetate, and vicriviroc. Molecules

1431 outside the dashed box (see labels within the figure) are those currently being considered

1432 for vaginal ring formulations and that, due to physiochemical constraints, generally

1433 require novel formulation approaches. Figure used with permission [10].

1434

1435 Fig. 2. Different type of shaking incubators commonly used for in vitro release testing of 1436 vaginal rings. A - a benchtop shaking incubator; B - a floor-standing top-opening orbital 1437 shaking incubator; C - stackable orbital shaking incubators; D - flasks containing

1438 suspended rings in vitro undergoing release testing in an orbital shaking incubator.

1440 Fig. 3. Sealed glass flasks for in vitro release testing of vaginal rings. A - ring placed on 1441 bottom of flask containing $100 \mathrm{~mL}$ of release medium. B - ring suspended by a nylon 1442 thread in glass flask containing $200 \mathrm{~mL}$ release medium.

1444 Fig. 4. Workflows describing methods for developing IVIVCs for matrix-type (A-D)

1445 and reservoir-type vaginal rings $(\mathrm{E}-\mathrm{H})$, where the in vivo parameter is the total dose

1446 administered at any time $t$. This dose is calculated by subtracting the value for the

1447 residual drug content in the ring after a specified period of clinical use (based on a

1448 solvent extraction method) from the value of the initial drug loading in the ring. Panels I

1449 and J illustrate other possible correlations based on use of either plasma AUC or

1450 measured drug concentration in a biological medium (usually plasma, vaginal tissue or

1451 vaginal fluid) as the readout for the in vivo parameter.

1453 Fig. 5. Biological compartments of a physiologically-based pharmacokinetic model for a 1454 drug-releasing vaginal ring. Figure adapted from [165]. 
1456 Fig. 6. Representative in vitro drug release vs. time profiles for matrix (A, C and E) and 1457 reservoir-type vaginal rings (B and D).

1458

\section{Table 1.}

1460 Descriptions of vaginal rings (both marketed products and products currently undergoing

1461 clinical testing) and details of in vitro testing methods.

1462

1463 Table 2. Factors that can potentially affect the in vitro drug release performance of

1464 vaginal rings.

1465

1466 Table 3. Equations that have been used to model in vitro release data for matrix-type and 1467 reservoir-type drug-releasing vaginal rings.

1468 